Sharif University of Technology
Scientia Iranica
Transactions E: Industrial Engineering
http://scientiairanica.sharif.edu
IRAN ICA

\title{
Closed-loop supply chain network design for the paper industry: A multi-objective stochastic robust approach
}

\author{
A. Rahmani Ahranjani ${ }^{a}$, M. Seifbarghy ${ }^{b}, *$ A. Bozorgi-Amiri ${ }^{c}$, and E. Najafi ${ }^{a}$ \\ a. Department of Industrial Engineering, Science and Research Branch, Islamic Azad University, Tehran, Iran. \\ b. Department of Industrial Engineering, Alzahra University, Tehran, Iran. \\ c. School of Industrial Engineering, College of Engineering, University of Tehran, Tehran, Iran.
}

Received 12 January 2017; received in revised form 3 August 2017; accepted 29 July 2017

\section{KEYWORDS}

Closed-loop supply chain network design;

Uncertainty modeling;

Multi-objective

optimization;

Paper industry.

\begin{abstract}
Closed-loop supply chain design is used to provide an optimal platform for efficient and effective supply chain management. It is an essential and strategic operation management problem in supply chain management and, usually, includes multiple and conflicting objectives. A new mixed integer non-linear programming model for a multi-objective closed-loop supply chain network design problem in the paper industry is developed under uncertainty. The objective functions can minimize the total cost, maximize the total volume flexibility, and minimize the total number of vehicles hired in order to fulfill the paper industry's policies towards a cleaner and green environment. In addition, a novel hybrid solution is presented based on stochastic programming, robust optimization, and fuzzy goal programming. A numerical example utilizing the real data from the paper industry in East Azerbaijan of Iran is designed, and the model performance is assessed. Furthermore, a recently developed Dragonfly Algorithm (DA) has been employed to solve the given problem on large scales and compared with Genetic Algorithm (GA). The results indicated that the DA achieved better performance, as compared with the GA.
\end{abstract}

(C) 2018 Sharif University of Technology. All rights reserved.

\section{Introduction}

The paper industry is one of the main industrial sectors in Iran. According to the FAO (Food and Agriculture Organization), Iran's annual consumption of paper is 1711 thousand tons with per capita consumption $22 \mathrm{~kg}, 70 \%$ of which is imported [1]. However, a large proportion of waste paper is discarded every year posing an enormous problem with health hazard and environmental damages, instead of being recovered and reused. Paper recovering rate in Iran is very low (about $11 \%$ ), but average rates in advanced countries such as those in Europe and the world average are

*. Corresponding author. Fax: +98217r207041

E-mail address: M.Seifbarghy@alzahra.ac.ir (M. Seifbarghy)

doi: $10.24200 /$ sci. 2017.4464
66 and 56.6, respectively [2]. In addition, increasing industrial development and rapid urbanization put tremendous pressure on the limited resources available. Economical, environmental, and legal obligations have a force on paper manufacturers and all other stakeholders of paper supply chains to conduct the reverse flows of the waste paper. Effective collection, recovery and proper disposal of waste paper without damaging the environment are influenced by facilities' location decisions, which are strategic and crucial. Therefore, the strategic planning problem is essential for the paper industry, and the multi-objective Closed-Loop Supply Chain (CLSC) network design models have been scarcely investigated in the literature. A recent review by Govindan et al. [3] emphasized the lack of multiobjective decision-making models, and stated that only $12.4 \%$ of the previous studies in Reverse Logistics (RL) and CLSC used multi-objective approaches. In addi- 
tion, one of the major challenges of designing CLSC networks is the simultaneous study of the forward and reverse flows. Uster et al. [4] emphasized that reverse flow networks, which are independent of the forward flows, will lead to an increase in infrastructure costs and potential profit decrease related to different recovery alternatives. Moreover, addressing uncertainty related to activities in the CLSC is another challenge. Effective CLSC management under an uncertain environment should be based on various decision support studies [5].

With regard to the matters enumerated, the aim of this research is to develop a new multi-objective, multi-echelon, multi-product and mixed integer nonlinear programming model for CLSC design problem in paper industry including alternative recovery options, such as recycling with technology selection and energy recovery under uncertainty. In the proposed model, the following objective functions are introduced: minimization of the total cost of CLSC which includes fixed setup costs, purchasing costs regarding materials and waste papers, production costs, transportation costs, collection costs, sorting costs, recycling costs, and disposal cost; maximization of the total volume flexibility that includes manufacturing, distribution, collection, and recycling volume flexibilities; finally, minimization of the total number of vehicles hired in order to fulfill paper industry's policies towards a cleaner and green environment. A novel hybrid solution is developed by combining stochastic programming, robust optimization, and Fuzzy Goal Programming (FGP). In addition, the proposed model is applied to an illustrative example designed utilizing real data of the paper industry in Iran. Furthermore, a recently developed DA has been employed to solve the given problem on large scales and compared with GA.

The structure of the current paper is organized as follows. In the next section, the literature review is presented. In Section 3, the developed model is characterized. The hybrid solution method and meta-heuristic algorithm are presented in Section 4. Section 5 presents a real case study and some sensitivity analyses. Section 6 is devoted to the performance evaluation of meta-heuristic algorithm. Lastly, in Section 7, the final conclusions are drawn and future work directions are discussed.

\section{Literature review}

Du and Evans [6] presented a bi-objective optimization model that minimized overall costs and total tardiness for a reverse logistic network for repair services and set a hybrid solution algorithm containing scatter search, the dual simplex, and the constraint method for solving the problem on large scales. Pishvaee et al. [7] proposed a bi-objective mixed integer linear programming model to minimize the total costs and maximize the responsiveness of a CLSC network and used a Memetic algorithm to solve it. Pishvaee and Torabi [8] introduced a bi-objective possibilistic optimization model that minimizes the total cost of CLSC and the total tardiness of delivered products. They used a fuzzy multiobjective programming approach to solve the problem. Mirakhorli [9] employed an interactive FGP method to solve the fuzzy multi-objective reverse logistics network design problem including minimization of the total cost and total transportation time with fuzzy demand and return-product. Khajavi et al. [10] proposed a biobjective mixed-integer programming model to minimize the total costs and maximize the responsiveness of the CLSC network and applied branch-and-bound method to find a global optimum for the proposed model. To minimize network design costs and total weighted tardiness of returning products to collection centers, a bi-objective mixed integer linear programming model was presented by Zegordi et al. [11]. To illustrate the applicability of the $\varepsilon$-constraint method, a numerical example was designed. Zarandi et al. [12] formulated a multi-objective optimization model that minimizes total cost, maximizes the total service level, and maximizes reverse service level of CLSC. To model and solve the problem, an interactive FGP approach was developed for network design.

Amin and Zhang [13] introduced a bi-objective facility location model for a general CLSC network to minimize the total costs and maximize environmental factors including environmentally-friendly materials and clean technology. They used a stochastic model for considering the uncertainty in the production phase. Özkır and Başlıgil [14] presented a fuzzy multi-objective optimization model for CLSC network design problem. Their model proposed profit maximization and customer satisfaction related to price adjustment and demand fulfillment as important objectives in a supply chain. They used a fuzzy programming approach to uncertainty. Subulan et al. [15] proposed a scenario-based stochastic and possibilistic mixed integer programming model for a multi-objective CLSC network design problem by considering financial and collection risks. The proposed hybrid model was applied to the lead/acid industry. Vahdani and Mohamadi [16] introduced a bi-objective interval-stochastic robust optimization model for designing CLSC network in which total costs and maximum waiting times in the queue of products were considered to minimize. They presented a self-adaptive imperialist competitive meta-heuristic algorithm to solve the proposed problem on a large scale. Kadambala et al. [17] proposed a multi-objective CLSC model to evaluate delay parameters with decision variables to maximize profit, optimize customer surplus, and minimize energy use. They employed a multi-objective particle swarm optimization approach 
to solve the proposed model. Soleimani et al. [18] presented a design problem of CLSC by accounting for environmental considerations, optimization of the total profit, and reduction of lost working days due to occupational accidents and maximized responsiveness to customer demand. They utilized genetic algorithm to solve the model and investigated multiple scenarios with different aspects. Paydar et al. [19] formulated a mixed-integer linear programming model for a CLSC of used engine oil. They used the robust optimization approach due to uncertainty in the amounts of collected oil in the engine oil RL and considered two objective functions of maximizing profit and minimizing the risk of the collection. They solved the proposed model with augmented $\varepsilon$-constraint approach.

Based on the aforementioned literature, the research gaps are as follows:

1. Discussion about robust RL \& CLSC design models is insufficient and there is a requirement for presenting robustness in RL \& CLSC design;

2. In few research papers, the researchers have proposed hybrid solutions including various uncertainty approaches in order to solve the CLSC problems;

3. Study of the literature shows that there is a lack of investigating multi-objective CLSC considering total cost, total volume flexibility, and total number of vehicles hired under uncertainty;

4. There is not enough approach to solving problems on large scales.

\section{Problem description and assumptions}

Paper as a key product needs an optimal CLSC network design. The scheme of the paper CLSC network structure is depicted in Figure 1. Different types of new paper are transported to the wholesalers to meet the paper dealers' demands in the forward supply chain. Furthermore, recycled paper is shipped from recycling facilities to the wholesalers to meet the secondary market needs. Collection centers collect waste paper from customer zones and supply it to the centralized collection points in the reverse chain, where the sorting for waste paper occurs. Based on the sorting process, the appropriate paper is shipped to the recycling facilities or sold for energy recovery while the contaminated paper is transported to the disposal sites. Incineration of waste paper with the production of steam for heating or electric power production is an accepted method of energy recovery [20]. Waste paper can be categorized into eleven easily identifiable types of paper. Of the eleven components, the newspaper has the highest calorific value, while the glossy paper

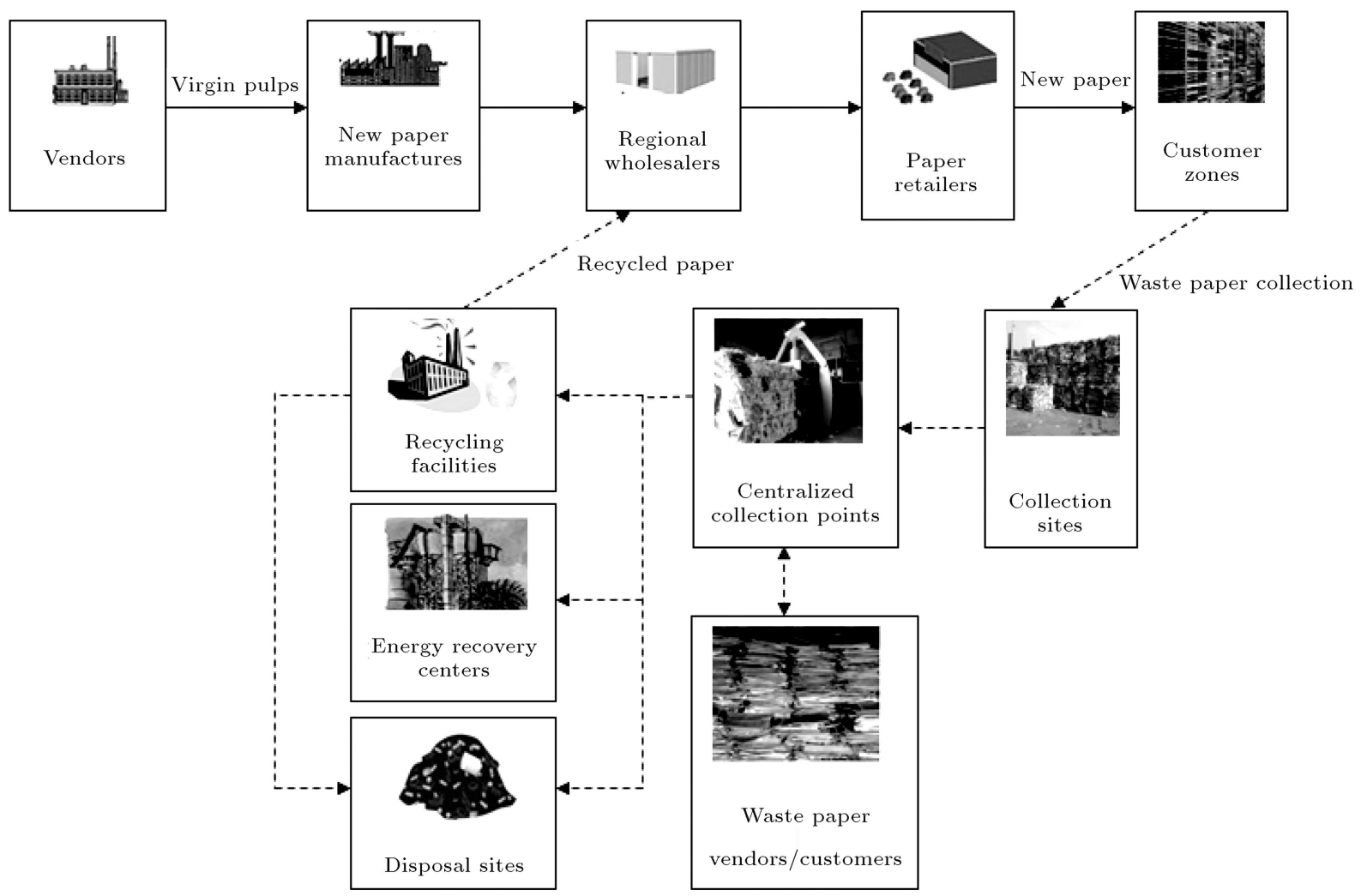

Figure 1. Presentation of the paper CLSC network. 
has the lowest calorific value. Cardboard and white office papers are appropriate for recycling, while the colored office paper and oily papers are suitable for incineration. Furthermore, regional wholesalers and centralized collection points can be used as temporary storage area for the waste paper. Additional waste paper can be purchased from the waste vendors in accordance with the requirement for waste paper. Appropriate processing technologies need to be installed at each recycling facility location depending on the type of the input materials and the requirements for the output materials.

In forward supply chain, large paper batches are required to be carried; therefore, the companies should go for a full transport load mode of transporting trucks. Conversely, while in the reverse supply chain, the paper required to be transported is low; hence, a lighter transport load mode of transportation is apt. In forward supply chain, the companies hire vehicles from 3PL providers. 3PL providers maintain a fleet of different types of vehicles with different capacities. Renting any vehicle depends on its capacity and engine efficiency. The companies aim to minimize the number of vehicles to be hired because they are aware of their impact on the environment. The reverse flow is different; all the stages, except the initial collection center, are of single echelon. The transportation of waste paper from initial collection centers to the centralized collection point is to be carried out by government-owned small trucks. In view of minimizing the number of trips and distance travelled by the trucks, the routing of trucks between the initial collection center and the centralized collection point is to be analyzed with these limitations:

1. Waste paper from each initial collection center will be collected;

2. The tour of any truck will start and end at the centralized collection point, and it will cover one or more initial collection centers;

3. Truck capacity limitations and tour length limit will be respected.

The proposed mathematical model will be developed based on the following assumptions:

- There are two different points for wholesalers to supply demands. One is achieving them from different manufacturers; the other is acquiring them by recycling from the recycling facilities;

- The dealers' demand forecasts, quantity of returned waste paper, storage capacity of regional wholesalers and centralized collection point, fixed set-up cost of facilities, production cost, purchasing, selling and transportation of waste paper cost, and collection and disposal cost are not exactly known and considered as stochastic parameters. We assume that subject matter experts can devise the probability of scenarios;

- Any centralized collection centre can purchase additional waste paper from the waste vendors for recycling in the case of need. Furthermore, this centralized collection centre can also sell a certain amount of their collected waste paper to the customers if it is the cost effective. However, selling and purchasing operation for the same type of waste paper cannot be done simultaneously; moreover, at most one option can be performed;

- It is assumed that locations of waste paper customers and vendors do not have an impact on the CLSC network design and have an infinite budget and capacity for waste paper purchasing or selling;

- Transportation cost of collecting waste paper centers from initial collection is borne by the government and is directly proportional to the total distance covered;

- All flexibility components are assumed to be of the same importance according to the Decision-Makers (DMs).

\subsection{Indices and sets}

$p \quad$ Index of paper types $p \in P$,

$p^{\prime} \quad$ Index of recycled paper types $p^{\prime} \in P^{\prime}$,

$v \quad$ Index of virgin pulps $v \in V$,

$i \quad$ Index of new paper manufacturers $i \in I$,

$w \quad$ Index of potential regional wholesalers $w \in W$,

$k \quad$ Index of paper dealers and retailers $k \in K$, Index of initial collection centers $j \in J$, Index of centralized collection points $l \in L$,

Index of potential recycling facilities $r \in R$,

Index of potential recycling technologies $h \in H$,

Index of energy recovery centers $b \in B$, Index of disposals sites $d \in D$,

$$
\text { Index of vendors } m \in M \text {, }
$$
index of vehicles at vendor nodes $v m \in V M$,

Index of vehicles at manufacture nodes $v i \in V I$,

Index of vehicles at regional wholesaler nodes $v w \in V W$,

$t \quad$ Index of government-owned small trucks at $t \in T$, 
Index of possible scenarios indexed by $s \in S$,

\subsection{Model parameters}

$f_{w s} \quad$ Fixed setup cost of regional wholesaler $w$ in scenario $s$,

$f_{r s} \quad$ Fixed setup cost of recycling facility $r$ in scenario $s$,

$f_{r h s} \quad$ Fixed setup cost of recycling facility $r$ using technology $h$ in scenario $s$,

$T C_{s} \quad$ Transportation cost from initial collection centers to centralized collection points in scenario $s$ (in terms of monetary unit per kilometer),

$T C_{p s} \quad$ Transportation cost of waste paper type $p$ in scenario $s$ (in terms of monetary unit per kilogram),

$T C_{p^{\prime} s} \quad$ Transportation cost of recycled paper type $p^{\prime}$ in scenario $s$ (in terms of monetary unit per kilogram),

$P R C_{p s} \quad$ Production cost of paper type $p$ in each new paper manufacturer in scenario $s$ (in terms of monetary unit per kilogram),

$P U C_{v m i} \quad$ Purchasing cost of virgin pulp type $v$ from vendor $m$ for manufacturer $i$ (in terms of monetary unit per kilogram),

$P U C_{p l s} \quad$ purchasing cost of waste paper type $p$ from any waste paper vendor for centralized collection point $l$ in scenario $s$ (in terms of monetary unit per kilogram),

$R C_{\text {prh }} \quad$ Recycling cost of waste paper type $p$ in recycling facility $r$ using technology $h$ (in terms of monetary unit per kilogram),

$C C_{p j s} \quad$ Collection costs of waste paper type $p$ through the initial collection center $j$ in scenario $s$ (in terms of monetary unit per kilogram),

$S C_{p l} \quad$ sorting costs of waste paper type $p$ through centralized collection point $l$ (in terms of monetary unit per kilogram),

$D I C_{p s} \quad$ Disposal cost of waste paper type $p$ in scenario $s$ (in terms of monetary unit per kilogram),

$h_{v m} \quad$ Hiring cost of a vehicle $v m$ at vendor nodes,

$h_{v i} \quad$ Hiring cost of a vehicle $v i$ at manufacturer nodes,

$h_{v w} \quad$ Hiring cost of a vehicle $v w$ at regional wholesaler nodes
$D E_{p k s}$

Demand of paper dealer $k$ for paper type $p$ in scenario $s$ (in terms of kilogram),

$D E_{p^{\prime} k s} \quad$ Demand of paper dealer $k$ for paper type $p^{\prime}$ in scenario $s$ (in terms of kilogram),

$S P_{p} \quad$ Sales price of waste paper type $p$ to energy recovery center (in terms of monetary unit per kilogram),

$S P_{p l s} \quad$ Sales price of waste paper type $p$ from centralized collection point $l$ to any waste paper consumer in scenario $s$ (in terms of monetary unit per kilogram),

$R E_{p j s} \quad$ Returned volume of waste paper type $p$ to the initial collection center $j$ in scenario $s$ (in terms of kilogram),

$\varepsilon_{p}, \beta_{p}, \tau_{p} \quad$ Fraction of waste paper type $p$ shipped from centralized collection point to recycling, energy recovery and disposal sites, respectively, noting that $\varepsilon_{p}+\beta_{p}+\tau_{p}=1$

$\sigma_{p} \quad$ Fraction of waste paper type $p$ satisfying the quality specifications for recycling process,

$\pi_{v p} \quad$ Amount of virgin pulp type $v$ to produce paper type $p$ (in terms of kilogram),

$W$ cap $_{w s} \quad$ Storage capacity of regional wholesaler $w$ for forward flows of paper in scenario $s$,

Prcap $_{p i} \quad$ Production capacity of new paper manufacturer $i$ for paper type $p$,

Ccapr $_{l s} \quad$ Storage capacity of centralized collection point $l$ for reverse flows of waste paper in scenario $s$,

Recap prh Recycling capacity of technology $h$ at recycling facility $r$ for waste paper type $p$,

$D_{j l} \quad$ The distance between initial collection center $j$ and centralized collection point $l$,

$D_{j j^{\prime}} \quad$ The distance between any two collection centers,

$V_{c a p} \quad$ Supply capacity of vendor $m$ for virgin pulp type $v$,

$C_{a p} \quad$ Capacity of vehicle $v m$ at vendor nodes (in terms of kilogram),

$\max _{v m} \quad$ Maximum number of vehicle type $v m$ available at vendor nodes,

$\mathrm{Cap}_{v i} \quad$ Capacity of vehicle vi at manufacturer nodes (in terms of kilogram), 

$\max _{v i} \quad$ Maximum number of vehicle type $v i$ available at manufacturer nodes,
Capw Capacity of vehicle $v w$ at regional wholesaler nodes (in terms of kilogram),

$\max _{v w} \quad$ Maximum number of vehicle type $v w$ available at regional wholesaler nodes,

Cap $\quad$ Capacity of government-owned small truck $t$ (in terms of kilogram),

$\max _{D t} \quad$ Maximum tour distance of governmentowned small truck $t$,

$\max _{t} \quad$ Maximum number of governmentowned small truck $t$,

$W_{1} \quad$ Weight of capacity utilization for manufacturing plants,

$W_{2} \quad$ Weight of capacity utilization for regional wholesalers,

$W_{3} \quad$ Weight of capacity utilization for centralized collection points,

$W_{4} \quad$ Weight of capacity utilization for recycling facilities,

$P_{s} \quad$ Occurrence probability of scenario $s$,

$N \quad$ Maximum number of opened wholesalers,

$M \quad$ An arbitrary set large number.

\subsection{Decision variables}

$W_{w} \quad 1$, if a regional wholesaler opens at location $w$; 0 , otherwise,

$R_{r} \quad 1$, if a recycling facility opens at location $r$; 0 , otherwise,

$H_{r h} \quad 1$, if a technology $h$ is activated at recycling location $r$; 0 , otherwise,

$Q_{p i s} \quad$ Production quantity of paper type $p$ in paper manufacturer $i$ in scenario $s$ (in terms of kilogram),

$X 1_{\text {piws }}^{v i} \quad$ Quantity of paper type $p$ shipped to the regional wholesaler $w$ from new paper manufacturer $i$ via vehicle $v i$ in scenario $s$ (in terms of kilogram),

$X 2_{\text {pwks }}^{v w} \quad$ Quantity of paper type $p$ shipped to dealer $k$ from regional wholesaler $w$ via vehicle $v w$ in scenario $\mathrm{s}$ (in terms of kilogram),

$X 3_{p^{\prime} \text { rws }} \quad$ Quantity of paper type $p^{\prime}$ shipped to regional wholesaler $w$ from recycling facility $r$ in scenario $s$ (in terms of kilogram),

$X 4_{p^{\prime} w k s}^{v w} \quad$ Quantity of paper type $p^{\prime}$ shipped to dealer $k$ from regional wholesaler $w$ via vehicle $v w$ in scenario $s$ (in terms of kilogram),
$X 5_{\text {plbs }} \quad$ Quantity of waste paper type $p$ shipped to energy recovery center $b$ from centralized collection center $l$ in scenario $s$ (in terms of kilogram),

$X 6_{\text {plds }} \quad$ Quantity of waste paper type $p$ shipped to disposal site $d$ from centralized collection center $l$ in scenario $s$ (in terms of kilogram),

$X 7_{\text {plrs }} \quad$ Quantity of waste paper type $p$ shipped to recycling facility $r$ from centralized collection center $l$ in scenario $s$ (in terms of kilogram),

$X 8_{\text {prds }} \quad$ Quantity of waste paper type $p$ shipped to disposal site $d$ from recycling facility $r$ in scenario $s$ (in terms of kilogram),

$Q P_{v m i s}^{v m} \quad$ Amount of virgin pulp $v$ purchased from vendor $m$ by new paper manufacturer $i$ via vehicle $v m$ in scenario $s$ (in terms of kilogram),

$Q V_{p l s} \quad$ Amount of waste paper type $p$ purchased by centralized collection center $l$ in scenario $s$ (in terms of kilogram),

$Q C_{p l s} \quad$ Amount of waste paper type $p$ sold to any waste paper customer from collection centralized collection center $l$ in scenario $s$ (in terms of kilogram),

$R E_{\text {prhs }} \quad$ Recycling quantity of waste paper type $p$ in technology $h$ at recycling facility $r$ in scenario $s$ (in terms of kilogram),

$N_{v m s} \quad$ Number of vehicle type $v m$ hired by vendor nodes in scenario $s$,

$N_{v i s} \quad$ Number of vehicle type $v i$ hired at manufacturer nodes in scenario $s$,

$N_{v w s} \quad$ Number of vehicle type $v w$ hired at regional wholesaler nodes in scenario $s$,

$Y_{w k s} \quad 1$, if regional wholesaler $w$ serves paper dealer $k$ for meeting its demand in the forward chain in scenario $s ; 0$, otherwise,

$Y_{j t s} \quad 1$, if initial collection center $j$ is served by vehicle $t$ in scenario s; 0 , otherwise,

$Y 1_{l j s} \quad 1$, if initial collection center $j$ is the successor of centralized collection point $l$ in scenario $s ; 0$, otherwise,

$Y_{j l s} \quad 1$, if centralized collection point $l$ is the successor of initial collection center $j$ in scenario $s ; 0$, otherwise,

$Y_{j j^{\prime} s} \quad 1$, if initial collection center $j$ is the successor of initial collection center $j^{\prime}$ in scenario $s$; 0 , otherwise, 

$Y 1_{p l s} \quad 1$, if centralized collection point $l$ sells waste paper type $p$ to any waste paper customer in scenario $s$; 0 , otherwise,
$Y_{p l s} \quad 1$, if centralized collection point $l$ purchases waste paper type $p$ from any waste paper vendor in scenario $s ; 0$, otherwise,
$L_{m i s}^{v m} \quad 1$, if a transportation link is established between vendor $m$ and manufacturer $i$ via mode $v m$ in scenario $s ; 0$, otherwise,
$L_{i w s}^{v i} \quad 1$, if a transportation link is established between manufacturer $i$ and regional wholesaler $w$ via mode $v i$ in scenario $s$; 0 , otherwise,
$L_{w k s}^{v w} \quad 1$, if a transportation link is established between regional wholesaler $w$ and dealer $k$ via mode $v w$ in scenario $s ; 0$, otherwise.

\subsection{Mathematical formulation of the problem} As mentioned, three objective functions are considered in the formulation of CLSC problem in paper industry:

1. Minimization of total CLSC cost;

2. Maximization of total volume flexibility;

3. Minimization of environmental impact by minimizing the total number of vehicles hired.

The first objective function is to minimize the total CLSC cost which is the summation of Fixed Opening Costs (FOC), purchasing costs (PUC), Production Costs (PC), Transportation Costs (TC), Collection Costs $(C C)$, Sorting Costs (SC), recycling costs (REC), and Disposal Costs (DC) minus revenue obtained from selling collected waste paper to energy recovery centers and waste paper customers as represented in Eqs. (1)(10):

$$
\begin{aligned}
F O C= & \sum_{w \in W} f_{w s} \cdot W_{w}+\sum_{r \in R} f_{r s} \cdot R_{r} \\
& +\sum_{r \in R} \sum_{h \in H} f_{r h s} \cdot H_{r h}
\end{aligned}
$$

$$
\begin{aligned}
P U C= & \sum_{v \in V} \sum_{m \in M} \sum_{i \in I} \sum_{v m \in V M} Q P_{v m i s}^{v m} \cdot P U C_{v m i} \\
& +\sum_{p \in P} \sum_{l \in L} Q V_{p l s} . P U C_{p l s},
\end{aligned}
$$$$
P C=\sum_{p \in P} \sum_{i \in I} Q_{p i s} . P R C_{p s},
$$

$$
\begin{aligned}
& T C=\sum_{v m \in V} \sum_{m \in M} \sum_{i \in I} h_{v m} \cdot N_{v m s} \cdot L_{m i s}^{v m} \\
& +\sum_{v i \in V I} \sum_{i \in I} \sum_{w \in W} h_{v i} \cdot N_{v i s} \cdot L_{i w s}^{v i} \\
& +\sum_{v w \in V W} \sum_{w \in W} \sum_{k \in K} h_{v w} \cdot N_{v w s} \cdot L_{w k s}^{v w} \\
& +\sum_{t \in T} T C_{s} \cdot\left(\sum_{l \in L} \sum_{j \in J} Y 1_{l j s} \cdot Y_{j t s} \cdot D_{j l}\right. \\
& \left.+\sum_{j \in J} \sum_{j^{\prime} \in J^{\prime}} Y_{j j^{\prime} s} \cdot Y_{j t s} \cdot D_{j j^{\prime}}+\sum_{j \in J} \sum_{l \in L} Y_{j l s} \cdot D_{j l}\right) \\
& +\sum_{p \in P} \sum_{l \in L} \sum_{b \in B} T C_{p s} . X 5_{p l b s} \\
& +\sum_{p \in P} \sum_{l \in L} \sum_{d \in D} T C_{p s} \cdot X 6_{p l d s} \\
& +\sum_{p \in P} \sum_{l \in L} \sum_{r \in R} T C_{p s} . X 7_{p l r s} \\
& +\sum_{p \in P} \sum_{r \in R} \sum_{d \in D} T C_{p s} . X 8_{p r d s} \\
& +\sum_{p^{\prime} \in P^{\prime}} \sum_{r \in R} \sum_{w \in W} T C_{p^{\prime} s} \cdot X 3_{p^{\prime} r w s} \\
& C C=\sum_{p \in P} \sum_{l \in L} \sum_{j \in J} Y 1_{l j s} . R E_{p j s} . C C_{p j s}, \\
& S C=\sum_{p \in P} \sum_{l \in L} \sum_{j \in J} Y 1_{l j s} . R E_{p j s} . S C_{p l} \\
& +\sum_{p \in P} \sum_{l \in L} Q V_{p l s} \cdot S C_{p l} \\
& R E C=\sum_{p \in P} \sum_{r \in R} \sum_{h \in H} R E 1_{p r h s} \cdot R C_{p r h}, \\
& D C=\sum_{p \in P} \sum_{l \in L} \sum_{d \in D} X 6_{p l d s} . D I C_{p s} \\
& +\sum_{p \in P} \sum_{r \in R} \sum_{d \in D} X 8_{p r d s} . D I C_{p s}, \\
& R E V=\sum_{p \in P} \sum_{l \in L} \sum_{b \in B} X 5_{p l b s} . S P_{p} \\
& +\sum_{p \in P} \sum_{l \in L} Q C_{p l s} . S P_{p l s},
\end{aligned}
$$




$$
\begin{aligned}
\min Z 1= & \sum_{s \in S} p_{s}\left[F O C_{s}+P U C_{s}+P C_{s}+T C_{s}\right. \\
& \left.+C C_{s}+S C_{s}+R E C_{s}+D C_{s}-R E V_{s}\right]
\end{aligned}
$$

Slack [21] and Sabri and Beamon [22] introduced two different flexibility categories, namely volume flexibility and delivery flexibility, which are expressed as "the ability to change the level of produced products and planned delivery dates". One can calculate the delivery and volume flexibilities by using lead time and capacity slacks, respectively. In practice, volume flexibility can be calculated as the difference between capacity and capacity utilization [23]. Vickery et al. [24] emphasized that flexibility was a significant concept for calculating supply chain performance and might be an opportunity to improve firms' sustainability and efficiency. Therefore, the second objective function is to maximize the total volume flexibility, which consists of manufacturing volume flexibility (PVF), Distribution Volume Flexibility (DVF), Collection Volume Flexibility (CVF), and Recycling Volume Flexibility (RVF) as represented in Eqs. (11)-(15):

$$
\begin{aligned}
& M V F= \sum_{i \in I}\left(\sum_{p \in P} \operatorname{Prcap}_{p i}-\sum_{p \in P} Q_{p i s}\right) \\
& D V F= \sum_{w \in W}\left(\text { Crapf }_{w s} . W_{w}\right. \\
&\left.-\sum_{p \in P} \sum_{p^{\prime} \in P^{\prime}} \sum_{k \in K} Y_{w k s} \cdot\left(D E_{p k s}+D E_{p^{\prime} k s}\right)\right) \\
& C V F= \sum_{l \in L}\left(C c a p r_{l s}-\left(\sum_{p \in P} \sum_{j \in J} Y 1_{j l s} . R E_{p j s}\right.\right. \\
&\left.\left.+\sum_{p \in P} Q V_{p l s}\right)\right) \\
& R V F= \sum_{r \in R}\left(\sum_{p \in P} \sum_{h \in H} R e c a p_{p r h} . H_{r h}\right. \\
&\left.-\sum_{p \in P} \sum_{h \in H} R E_{p r h s}\right) \\
& R
\end{aligned}
$$

$$
\begin{aligned}
\max Z 2= & \sum_{s \in S} p_{s}\left[W_{1} \cdot M V F_{s}+W_{2} \cdot D V F_{s}\right. \\
& \left.+W_{3} \cdot C V F_{s}+W_{4} \cdot R V F_{s}\right] .
\end{aligned}
$$

The third objective function is to minimize the transporting trucks in the forward supply chain to control the impact of the paper network on the environment. Because the companies in our case study use a large number of transporting trucks in the forward supply chain, this employment leads to a large amount of greenhouse gas emissions. Hiring more than one vehicle of lesser capacity is cheaper than hiring a vehicle with a larger capacity [25]. Thus, in order to achieve the paper industry's policies regarding a cleaner and green environment, the companies aim to minimize the number of vehicles hired in the forward supply chain. Hence, the third objective is represented in Eq. (16):

$$
\min Z 3=\sum_{v m \in V M} N_{v m s}+\sum_{v i \in V I} N_{v i s}+\sum_{v w \in V W} N_{v w s}
$$

Constraints are expressed by Eqs. (17)-(60):

$$
\begin{array}{lc}
\sum_{k \in K} Y_{w k s} \leq M \cdot W_{w} & \forall w, \forall s, \\
\sum_{w \in W} Y_{w k s}=1 & \forall k, \forall s, \\
\sum_{w \in W} W_{w} \leq N & \forall s, \\
\sum_{p \in P} \sum_{p^{\prime} \in P^{\prime}} \sum_{k \in K} Y_{w k s} \cdot\left(D E_{p k s}+D E_{p^{\prime} k s}\right) \\
\leq W c a p_{w s} . W_{w} & \forall w, \forall s,
\end{array}
$$

$$
\begin{aligned}
& \sum_{i \in I} \sum_{v i \in V I} X 1_{\text {piws }}^{v i}=\sum_{k \in K} \sum_{v w \in V W} X 2_{\text {pwks }}^{v w} \\
& \forall p, \forall w, \forall s, \\
& \sum_{r \in R} X 3_{p^{\prime} \text { rws }}=\sum_{k \in K} \sum_{v w \in V W} X 4_{p^{\prime} w k s}^{v w} \\
& \forall p^{\prime}, \forall w, \forall s,
\end{aligned}
$$

$\sum_{v w \in V W} \sum_{p \in P} X 2_{p w k s}^{v w}=\sum_{p \in P} D E_{p k s} . Y_{w k s}$

$\forall w, \forall k, \forall s$,

$\sum_{v w \in V W} \sum_{p^{\prime} \in P^{\prime}} X 4_{p^{\prime} w k s}^{v w}=\sum_{p^{\prime} \in P^{\prime}} D E_{p^{\prime} k s} . Y_{w k s}$

$\forall w, \forall k, \forall s$,

$$
\sum_{w \in W} \sum_{v i \in V I} X 1_{\text {piws }}^{v i} \leq Q_{p i s} \quad \forall p, \forall i, \forall s
$$

$$
Q_{p i s} \leq \text { Prcap }_{p i} \quad \forall p, \forall i, \forall s,
$$




$$
\begin{gathered}
\sum_{p \in P} \sum_{j \in J} Y 1_{l j s} . R E_{p j s}+\sum_{p \in P} Q V_{p l s}-\sum_{p \in P} Q C_{p l s} \\
\leq C \text { capr } l s \quad \forall l, \forall s,
\end{gathered}
$$

$$
\sum_{b \in B} X 5_{p l b s}=\varepsilon_{p} \cdot\left(\sum_{j \in J} Y 1_{l j s} . R E_{p j s}+Q V_{p l s}-Q C_{p l s}\right)
$$$$
\forall p, \forall l, \forall s,
$$$$
\sum_{d \in D} X 6_{p l d s}=\beta_{p} \cdot\left(\sum_{j \in J} Y 1_{l j s} \cdot R E_{p j s}+Q V_{p l s}-Q C_{p l s}\right)
$$$$
\forall p, \forall l, \forall s,
$$

$$
\begin{aligned}
& \sum_{r \in R} X 7_{p l r s}=\tau_{p} \cdot\left(\sum_{j \in J} Y 1_{l j s} \cdot R E_{p j s}+Q V_{p l s}-Q C_{p l s}\right) \\
& \quad \forall p, \forall l, \forall s,
\end{aligned}
$$

$$
\sum_{h \in H} R E_{p r h s}=\sigma_{p} \cdot \sum_{l \in L} X 7_{p l r s}
$$$$
\forall p, \forall r, \forall s,
$$

$$
\begin{gathered}
R E_{p r h s} \leq H_{r h} . \text { Recap }_{p r h} \\
\forall p, \forall r, \forall h, \forall s,
\end{gathered}
$$$$
\sum_{w \in W} X 3_{p^{\prime} r w s} \leq \sum_{h \in H} R E_{\text {prhs }}
$$$$
\forall p^{\prime}, \forall p, \forall r, \forall s,
$$$$
\sum_{d \in D} X 8_{p r d s}=\left(1-\sigma_{p}\right) \cdot \sum_{l \in L} X 7_{p l r s}
$$

$$
\forall p, \forall r, \forall s,
$$$$
\sum_{h \in H} H_{r h}=R_{r} \quad \forall r, \forall s,
$$

$\sum_{i \in I} \sum_{v m \in V M} Q P_{v m i s}^{v m} \leq V c a p_{v m}$

$\forall v, \forall m, \forall s$,

$$
\begin{aligned}
& \sum_{m \in M} \sum_{v m \in V M} Q P_{v m i s}^{v m}=\sum_{p \in P} Q_{p i s} . \pi_{v p} \\
& \forall v, \forall i, \forall s, \\
& Q V_{p l s} \leq M . Y_{p l s} \quad \forall p, \forall l, \forall s,
\end{aligned}
$$

$$
L_{i w s}^{v i} \leq \sum_{p \in P} X 1_{p i w s}^{v i} \quad \forall i, \forall w, \forall v i, \forall s
$$$$
L_{w k s}^{v w} \leq \sum_{p \in P} X 2_{p w k s}^{v w}+\sum_{p^{\prime} \in P^{\prime}} X 4_{p^{\prime} w k s}^{v w}
$$

$$
\forall w, \forall k, \forall v w, \forall s,
$$

$$
N_{v m s} \leq \max _{v m} \quad \forall v m, \forall s,
$$$$
\sum_{p \in P} \sum_{i \in I} \sum_{w \in W} X 1_{p i w s}^{v i} \leq N_{v i s} . C a p_{v i} \quad \forall v i, \forall s,
$$

$\sum_{p \in P} \sum_{w \in W} \sum_{k \in K} X 2_{p w k s}^{v w}+\sum_{p^{\prime} \in P^{\prime}} \sum_{w \in W} \sum_{k \in K} X 4_{p^{\prime} w k s}^{v w}$

$$
N_{v w s} \leq \max _{v w} \quad \forall v w, \forall s,
$$

$$
L_{m i s}^{v m} \leq \sum_{v \in V} Q P_{v m i s}^{v m} \quad \forall m, \forall i, \forall v m, \forall s,
$$

$$
\sum_{v \in V} Q P_{v m i s}^{v m} \leq M \cdot L_{m i s}^{v m}
$$

$$
\forall m, \forall i, \forall v m, \forall s,
$$

$$
\sum_{p \in P} X 1_{\text {piws }}^{v i} \leq M \cdot L_{\text {iws }}^{v i}
$$

$$
\forall i, \forall w, \forall v i, \forall s,
$$

$$
\sum_{p \in P} X 2_{p w k s}^{v w}+\sum_{p^{\prime} \in P^{\prime}} X 4_{p^{\prime} w k s}^{v w} \leq M \cdot L_{w k s}^{v w}
$$

$$
\forall w, \forall k, \forall v w, \forall s,
$$




$$
\begin{aligned}
& \sum_{l \in L} \sum_{j \in J} Y 1_{l j s} \cdot Y_{j t s} . D_{j l}+\sum_{j \in J} \sum_{j^{\prime} \in J^{\prime}} Y_{j j^{\prime} s} \cdot Y_{j t s} \cdot D_{j j^{\prime}} \\
& \quad+\sum_{j \in J} \sum_{l \in L} Y_{j l s} \cdot D_{j l} \leq \max D_{t} \quad \forall t, \forall s, \\
& \sum_{j \in J} \sum_{p \in P} R E_{p j s} . Y_{j t s} \leq \max _{t} \cdot C a p_{t} \quad \forall t, \forall s, \\
& \sum_{l \in L} \sum_{t \in T} Y 1_{l j s} \cdot Y_{j t s}+\sum_{j^{\prime} \in J^{\prime}} \sum_{t \in T} Y_{j j^{\prime} s} . Y_{j t s}=1 \\
& \forall j, \forall s, \\
& \sum_{l \in L} \sum_{j \in J} Y 1_{l j s} \cdot Y_{j t s}=1 \quad \forall t, \forall s, \\
& \sum_{j \in J} \sum_{l \in L} Y_{j l s} . Y_{j t s}=1 \\
& W_{w}, R_{r}, H_{r h}, Y_{w k s}, Y_{j t s}, Y 1_{l j s}, Y_{j l s}, Y_{j j^{\prime} s}, Y 1_{p l s}, \\
& Y_{p l s}, L_{m i s}^{v m}, L_{i w s}^{v i}, L_{w k s}^{v w} \in(0,1), \\
& N_{v m s}, N_{v i s}, N_{v w s} \geq 0, \quad \forall t, \forall s, \\
& \text { and integer. }
\end{aligned}
$$

All other varibles are continuous $\geq 0$.

According to Constraint (17), a regional wholesaler may serve any dealer if it is open. Constraint (18) ensures that the demands of the paper dealers be satisfied by a single regional wholesaler. Constraint (19) gives an upper bound for the number of regional wholesalers to be opened. Constraint (20) limits the amount of newly produced and recycled paper shipped through the regional wholesaler to its capacity of performing forward flows. Based on Constraints (21) and (22), the flow entering each regional wholesaler is equal to that exiting from the regional wholesaler. Constraints (23) and (24) ensure that the demands of paper dealers for newly produced and recycled paper can be satisfied. Constraint (25) guarantees that the outgoing flows from a new paper manufacturer cannot exceed the production quantity of that manufacturer. Constraint (26) ensures that the production quantity of each paper type cannot exceed the production capacity of the new paper manufacturers. Capacities of centralized collection centers are restricted by Constraint (27). Constraints (28) to (30) ensure that the sum of the waste paper taken from a centralized collection point to recycling facilities, energy recovery centers, and disposal sites cannot exceed the amount of waste paper available at the centralized collection center. Constraint (31) represents that the input rate of waste paper is satisfied with the quality specifications for the recycling process. According to Constraint (32), the recycling quantity of each paper type cannot be over the recycling capacity of different technologies of recycling center. Constraint (33) guarantees that the outgoing flows from a recycling center cannot exceed the recycling quantity at each recycling center. Constraint (34) represents the flow of non-recyclable waste paper from recycling facilities to disposal centers. Constraint (35) guarantees that each opened facility location has exactly one technology in use at each time. Constraint (36) gives the capacity constraint for vendors. Constraint (37) gives the authorized share of virgin pulp in order to satisfy quality conditions for paper types. Constraints (38) and (39) control the values of quantity variables. Constraint (40) ensures that purchasing and selling operations for the same type of waste paper cannot be done simultaneously within a single period time. According to Constraint (41), the maximum capacity of truck vm used in vendor $m$ should be investigated and dealt with. Constraint (42) shows that the number of the vmth trucks required by vendor cannot exceed the number of the $v m$ th trucks available. Similarly, Constraints (43)(44) are for manufacturers and constraints (45)-(46) are for regional wholesalers. Constraints (47)-(49) ensure that there are no links between any two locations through any truck without an actual transportation link. Constraints (50)-(52) ensure that there is no shipment between any non-linked locations for each type of vehicle. Constraints (53) and (54) ensure that maximum tour distance and maximum capacity should not exceed the allotted maximum distance and the capacity of the truck, respectively. Constraint (55) implies that every initial collection center serves and belongs to exactly one tour. Constraints (56) and (57) require every tour to start and end at the centralized collection points; thus, no invalid tour can be constructed. Constraints (58) and (59) impose the binary, non-negativity and integer restrictions on the corresponding decision variables. Constraint (60) ensures the non-negativity of other variables.

\subsection{Linearization}

Due to the multiplication of the binary and integer variables and binary variables in the first objective function and constraints, the stochastic model is nonlinear. To convert the model into its equivalent linear form, each type of non-linearity is considered in a separate way as follows.

\subsubsection{Product of binary and integer variables}

According to Eqs. (1) to (3) terms of TC in the first objective function, we have a multiplication of integer and binary variables. To transform these terms to the linear counterpart, $M$ is used as a reasonably large number. 


$$
\begin{aligned}
& G 1_{m i s}^{v m} \geq N_{v m s}-M\left(1-L_{m i s}^{v m}\right) \\
& \forall m, \forall i, \forall v m, \forall s, \\
& G 1_{m i s}^{v m} \leq M . L_{m i s}^{v m} \quad \forall m, \forall i, \forall v m, \forall s, \\
& G 1_{m i s}^{v m} \leq N_{v m s} \quad \forall m, \forall i, \forall v m, \forall s, \\
& G 2_{i w s}^{v i} \geq N_{v i s}-M\left(1-L_{i w s}^{v i}\right) \\
& \forall i, \forall w, \forall v i, \forall s, \quad \forall i, \forall w, \forall v i, \forall s, \\
& G 2_{i w s}^{v i} \leq M . L_{i w s}^{v i} \quad \forall i, \forall w, \forall v i, \forall s, \\
& G 2_{i w s}^{v i} \leq N_{v i} \quad \forall \\
& G 3_{w k s}^{v w} \geq N_{v w s}-M\left(1-L_{w k s}^{v w}\right) \\
& \forall w, \forall k, \forall v w, \forall s, \\
& G 3_{w k s}^{v w} \leq M . L_{w k s}^{v w} \quad \forall w, \forall k, \forall v w, \forall s, \\
& G 3_{w k s}^{v w} \leq N_{v w} \quad \forall w, \forall k, \forall v w, \forall s, \\
& G 1_{m i s}^{v m}, G 2_{i w s}^{v i}, G 3_{w k s}^{v w} \geq 0 \quad \text { and integer. }
\end{aligned}
$$

The transformations assure that in case of $L_{m i s}^{v m}$, $L_{i w s}^{v i}, L_{w k s}^{v w}=0$, there will be no vehicles between the concerned facilities; for $L_{m i s}^{v m}, L_{i w s}^{v i}, L_{w k s}^{v w}=1$, there will be flows between the concerned facilities.

\subsubsection{Product of two binary variables}

According to the fourth and fifth terms of TC in the first objective function and Constraints (53) and (55)(57), two binary variables multiply each other. For converting these terms to the linear one, the following constraints should be defined:

$$
\begin{array}{ll}
G 4_{l j t s} \leq Y 1_{l j s} & \forall l, \forall j, \forall t, \forall s, \\
G 4_{l j t s} \leq Y_{j t s} & \forall l, \forall j, \forall t, \forall s, \\
Y 1_{l j s}+Y_{j t s}-G 4_{l j t s} \leq 1 & \forall l, \forall j, \forall t, \forall s, \\
G 5_{j j^{\prime} t s} \leq Y_{j j^{\prime} s} & \forall j, \forall j^{\prime}, \forall t, \forall s, \\
G 5_{j j^{\prime} t s} \leq Y_{j t s} & \forall j, \forall j^{\prime}, \forall t, \forall s, \\
Y_{j j^{\prime} s}+Y_{j t s}-G 5_{j j^{\prime} t s} \leq 1 & \forall j, \forall j^{\prime}, \forall t, \forall s, \\
G 6_{j l t s} \leq Y_{j l s} & \forall j, \forall l, \forall t, \forall s, \\
G 6_{j l t s} \leq Y_{j t s} & \forall j, \forall l, \forall t, \forall s, \\
Y_{j l s}+Y_{j t s}-G 6_{j l t s} \leq 1 & \forall j, \forall l, \forall t, \forall s, \\
G 4_{l j t s}, G 5_{j j^{\prime} t s}, G 6_{j l t s} \in\{0,1\},
\end{array}
$$

where $G 4_{l j t s}$ is a binary variable that takes 1 if only both $Y 1_{l j s}$ and $Y_{j t s}$ take 1 . Then, terms of TC in the first objective function should be converted as follows:

$$
\begin{aligned}
& T C^{\prime}=\sum_{v m \in V M} \sum_{m \in M} \sum_{i \in I} h_{v m} \cdot G 1_{m i s}^{v m} \\
& +\sum_{v i \in V I} \sum_{i \in I} \sum_{w \in W} h_{v i} \cdot G 2_{i w s}^{v i} \\
& +\sum_{v w \in V W} \sum_{w \in W} \sum_{k \in K} h_{v w} \cdot G 3_{w k s}^{v w} \\
& +\sum_{t \in T} \mathrm{TC}_{s} \cdot\left(\sum_{l \in L} \sum_{j \in J} G 4_{l j t s} . D_{j l}\right. \\
& +\sum_{j \in J} \sum_{j^{\prime} \in J^{\prime}} G 5_{j j^{\prime} t s} \cdot D_{j j^{\prime}} \\
& \left.+\sum_{j \in J} \sum_{l \in L} Y_{j l s} \cdot D_{j l}\right) \\
& +\sum_{p \in P} \sum_{l \in L} \sum_{b \in B} \mathrm{TC}_{p s} . X 5_{p l b s} \\
& +\sum_{p \in P} \sum_{l \in L} \sum_{d \in D} \mathrm{TC}_{p s} \cdot X 6_{p l d s} \\
& +\sum_{p \in P} \sum_{l \in L} \sum_{r \in R} \mathrm{TC}_{p s} \cdot X 7_{p l r s} \\
& +\sum_{p \in P} \sum_{r \in R} \sum_{d \in D} \mathrm{TC}_{p s} . X 8_{p r d s} \\
& +\sum_{p^{\prime} \in P^{\prime}} \sum_{r \in R} \sum_{w \in W} \mathrm{TC}_{p^{\prime} s} . X 3_{p^{\prime} r w s} .
\end{aligned}
$$

In addition, Constraints (53) and (55)-(57) should be converted as follows:

$$
\begin{array}{ll}
\sum_{l \in L} \sum_{j \in J} G 4_{l j t s} \cdot D_{j l}+\sum_{j \in J} \sum_{j^{\prime} \in J^{\prime}} G 5_{j j^{\prime} t s} \cdot D_{j j^{\prime}} \\
+\sum_{j \in J} \sum_{l \in L} Y_{j l s} . D_{j l} \leq \max D_{t} \quad \forall t, \forall s, \\
\sum_{l \in L} \sum_{t \in T} G 4_{l j t s}+\sum_{j^{\prime} \in J^{\prime}} \sum_{t \in T} G 5_{j j^{\prime} t s}=1 & \forall j, \forall s, \\
\sum_{l \in L} \sum_{j \in J} G 4_{l j t s}=1 & \forall t, \forall s, \\
\sum_{j \in J} \sum_{l \in L} G 6_{j l t s}=1 & \forall t, \forall s .
\end{array}
$$




\section{The proposed solution methods}

\subsection{Uncertainty approach}

Some parameters such as cost, storage capacity, demand and returned waste paper are not exactly known and are uncertain in real-life problems, since the mentioned parameters are proposed as uncertain in our considered model in order to solve a realistic problem. Subsequently, a novel hybrid solution based on stochastic programming, robust optimization, and FGP is introduced to solve the proposed model.

\subsubsection{Stochastic robust optimization}

The integration of stochastic and robust optimization concerns the formulation of a stochastic robust optimization model, which can be written as follows [26]:

$$
\begin{aligned}
\min Z= & \sum_{s \in S} p_{s} \cdot \xi_{s}+\lambda \sum_{s \in S} p_{s}\left[\left(\xi_{s}-\sum_{s^{\prime} \in S^{\prime}} p_{s^{\prime}} \xi_{s^{\prime}}\right)+2 \theta_{s}\right] \\
& +\omega \sum_{s \in S} p_{s} \delta_{s}
\end{aligned}
$$

s.t.:

$$
\xi_{s}-\sum_{s^{\prime} \in S^{\prime}} p_{s^{\prime}} \xi_{s^{\prime}}+\theta_{s} \geq 0
$$

$$
A X \geq B
$$

$$
C_{s} X+D_{s} Y_{s}+\delta_{s} \geq E_{s} \quad \text { for all } s \in \Omega
$$

$X \geq 0, \quad Y_{s} \geq 0, \quad \theta_{s} \geq 0 \quad$ for all $s \in \Omega$

where $\lambda$ and $\omega$ show weight coefficients; $X$ and $Y_{s}$ present the structural and control variables, respectively. $A, C_{s}, D_{s}$ are parameter matrices, while $B$, $E_{s}$ are parameter vectors. $\delta_{s}$ is the vector of constraint deviation. The uncertain variables are expressed into values under $S$ scenarios $(\Omega=\{1,2, \cdots, s, \cdots, S\})$. Each scenario $(s \in \Omega$ ) belongs to a probability level $\left(p_{s}\right)$, where $\sum_{s \in S} p_{s}=1 . \xi_{s}$ is the random objective function value under scenario $s$ with probability level of $p_{s}$. In other words, $\theta_{s}=0$ since the amount of $\xi_{s}$ is greater than $\sum_{s \in S} p_{s} \xi_{s}$, while $\theta_{s}=\sum_{s \in S} p_{s} \xi_{s}-\xi_{s}$ since the amount of $\sum_{s \in S} p_{s} \xi_{s}$, is greater than $\xi_{s}$. The solution robustness is mentioned in the first terms of Eq. (86), while the model robustness is expressed in the last term.

Based on the above descriptions, the proposed model can be transformed as follows:

$$
\begin{aligned}
\min Z 1 & =\sum_{s \in S} p_{s}\left(F O C_{s}+P U C_{s}+P C_{s}+T C_{s^{\prime}}^{\prime}\right. \\
& \left.+C C_{s}+S C_{s}+R E C_{s}+D C_{s}-R E V_{s}\right)
\end{aligned}
$$

$$
\begin{aligned}
& +\lambda_{1} \cdot \sum_{s \in S} p_{s}\left[\left(\left(F O C_{s}+P U C_{s}+P C_{s}\right.\right.\right. \\
& +T C_{s}^{\prime}+C C_{s}+S C_{s}+R E C_{s}+D C_{s} \\
& \left.-R E V_{s}\right)-\sum_{s^{\prime} \in S^{\prime}} p_{s^{\prime}}\left(F O C_{s^{\prime}}+P U C_{s^{\prime}}\right. \\
& +P C_{s^{\prime}}+T C_{s^{\prime}}^{\prime}+C C_{s^{\prime}}+S C_{s^{\prime}}+R E C_{s^{\prime}} \\
& \left.\left.\left.+D C_{s^{\prime}}-R E V_{s^{\prime}}\right)\right)+2 \theta_{1 s}\right] \\
& +\omega\left[\sum_{w \in W} \sum_{s \in S} p_{s} . \delta 1_{w s}+\sum_{l \in L} \sum_{s \in S} p_{s} . \delta 2_{l s}\right],
\end{aligned}
$$

$$
\begin{aligned}
\max Z 2= & \sum_{s \in S} p_{s}\left(W_{1} \cdot M V F_{s}+W_{2} \cdot D V F_{s}\right. \\
& \left.+W_{3} \cdot C V F_{s}+W_{4} \cdot R V F_{s}\right) \\
& +\lambda_{2} \sum_{s \in S} p_{s}\left[\left(\left(W_{1} \cdot M V F_{s}+W_{2} \cdot D V F_{s}\right.\right.\right. \\
& \left.+W_{3} \cdot C V F_{s}+W_{4} \cdot R V F_{s}\right) \\
& -\sum_{s^{\prime} \in S^{\prime}} p_{s^{\prime}}\left(W_{1} \cdot M V F_{s^{\prime}}+W_{2} \cdot D V F_{s^{\prime}}\right. \\
& \left.\left.\left.+W_{3} \cdot C V F_{s^{\prime}}+W_{4} \cdot R V F_{s^{\prime}}\right)\right)-2 \theta_{2 s}\right]
\end{aligned}
$$

$$
\begin{aligned}
\min Z 3= & \sum_{s \in S} p_{s}\left(\sum_{v m \in V M} N_{v m s}+\sum_{v i \in V I} N_{v i s}\right. \\
& \left.+\sum_{v w \in V W} N_{v w s}\right) \\
& +\lambda_{3} \sum_{s \in S} p_{s}\left[\left(\sum_{v m \in V M} N_{v m s}+\sum_{v i \in V I} N_{v i s}\right.\right. \\
& \left.+\sum_{v w \in V W} N_{v w s}\right) \\
& -\sum_{s^{\prime} \in S^{\prime}} p_{s^{\prime}}\left(\sum_{v m \in V M} N_{v m s^{\prime}}+\sum_{v i \in V I} N_{v i s^{\prime}}\right. \\
& \left.\left.\left.+\sum_{v w \in V W} N_{v w s^{\prime}}\right)\right)+2 \theta_{3 s}\right]
\end{aligned}
$$


s.t.

$$
\begin{aligned}
\left(F O C_{s}\right. & +P U C_{s}+P C_{s}+T C_{s}^{\prime}+C C_{s}+S C_{s} \\
& \left.+R E C_{s}+D C_{s}-R E V_{s}\right)-\sum_{s^{\prime} \in S^{\prime}} p_{s^{\prime}}\left(F O C_{s^{\prime}}\right. \\
& +P U C_{s^{\prime}}+P C_{s^{\prime}}+T C_{s^{\prime}}^{\prime}+C C_{s^{\prime}}+S C_{s^{\prime}} \\
& \left.+R E C_{s^{\prime}}+D C_{s^{\prime}}-R E V_{s^{\prime}}\right)+\theta_{1 s} \geq 0
\end{aligned}
$$$$
\forall s \in S
$$

$\left(W_{1} \cdot M V F_{s}+W_{2} \cdot D V F_{s}+W_{3} \cdot C V F_{s}+W_{4} \cdot R V F_{s}\right)$

$$
\begin{aligned}
& -\sum_{s^{\prime} \in S^{\prime}} p_{s^{\prime}}\left(\left(W_{1} \cdot M V F_{s^{\prime}}+W_{2} \cdot D V F_{s^{\prime}}\right.\right. \\
& \left.+W_{3} \cdot C V F_{s^{\prime}}+W_{4} \cdot R V F_{s ;}\right)-\theta_{2 s} \geq 0
\end{aligned}
$$

$\forall s \in S$

$$
\begin{gathered}
\left(\sum_{v m \in V M} N_{v m s}+\sum_{v i \in V I} N_{v i s}+\sum_{v w \in V W} N_{v w s}\right) \\
-\sum_{s^{\prime} \in S^{\prime}} p_{s^{\prime}}\left(\sum_{v m \in V M} N_{v m s^{\prime}}+\sum_{v i \in V I} N_{v i s^{\prime}}\right. \\
\left.+\sum_{v w \in V W} N_{v w s^{\prime}}\right)+\theta_{3 s} \geq 0
\end{gathered}
$$

$\forall s \in S$,

$$
\begin{aligned}
& \sum_{p \in p} \sum_{p^{\prime} \in P^{\prime}} \sum_{k \in K} Y_{w k s} \cdot\left(D E_{p k s}+D E_{p^{\prime} k s}\right) \\
& \leq W \operatorname{cap}_{w s} \cdot W_{w}-\delta 1_{w s} \cdot W_{w} \quad \forall w, \forall s \\
& \sum_{p \in P} \sum_{j \in J} Y 1_{j l s} \cdot R E_{p j s}+\sum_{p \in P} Q V_{p l s}-\sum_{p \in P} Q C_{p l s} \\
& \leq C c a p r_{l}-\delta 2_{l s} \quad \forall l, \forall s, \\
& \delta 1_{w s}, \delta 2_{l s}, \theta_{1 s}, \theta_{2 s}, \theta_{3 s} \geq 0 .
\end{aligned}
$$

Constraints (17)-(19), (21)-(26), (28)-(52), (54), (58)(80) and (82)-(85).

Due to the multiplication of the binary and continuous variables in Constraint (97), the stochastic robust model is non-linear. To convert the model into its equivalent linear form, this type of non-linearity is considered as in the following:

$$
\begin{array}{ll}
G 7_{w s} \geq \delta 1_{w s}-M\left(1-W_{w}\right) & \forall w, \forall s, \\
G 7_{w s} \leq M . W_{w} & \forall w, \forall s, \\
G 7_{w s} \leq \delta 1_{w s} & \forall w, \forall s, \\
G 7_{w s} \geq 0 . &
\end{array}
$$

Then, Constraint (97) should be converted as follows:

$$
\begin{aligned}
& \sum_{p \in P} \sum_{p^{\prime} \in P^{\prime}} \sum_{k \in K} Y_{w k s} \cdot\left(D E_{p k s}+D E_{p^{\prime} k s}\right) \\
& \leq W \operatorname{cap}_{w s} . W_{w}-G 7_{w s} \quad \forall w, \forall s,
\end{aligned}
$$

\subsection{The proposed hybrid solution approach}

A novel hybrid solution is presented by combining the presented method in the previous section with FGP to solve the proposed model. The steps of the proposed hybrid solution can be summarized as follows:

Step 1: Verify all uncertain parameters, variables and their related distribution functions.

Step 2: Derive multi-objective stochastic robust model.

Step 3: Convert the stochastic robust optimization model to their respective crisp.

Step 4: Solve the model for each objective separately. If all the solutions are the same, select one of them as an optimal compromise solution. Otherwise, go to Step 5.

Step 5: Determine the range of each objective function over the efficient set by calculating the optimal and nadir solutions for each objective function. The optimal solutions, i.e., $\left(Z_{1}^{\text {optimal }}, x_{1}^{\text {optimal }}\right),\left(Z_{2}^{\text {optimal }}\right.$, $\left.x_{2}^{\text {optimal }}\right)$, and $\left(Z_{3}^{\text {optimal }}, x_{3}^{\text {optimal }}\right)$, are obtained from Step 4 by solving each objective function separately; the nadir solution for each objective function can be obtained from Eqs. (105) to (107):

$$
\begin{aligned}
& Z_{1}^{\text {nadir }}=\max \left(Z_{1}\left(x_{2}^{\text {optimal }}\right) \text { and } Z_{1}\left(x_{3}^{\text {optimal }}\right)\right) \\
& Z_{2}^{\text {nadir }}=\min \left(Z_{2}\left(x_{1}^{\text {optimal }}\right) \text { and } Z_{2}\left(x_{3}^{\text {optimal }}\right)\right) \\
& Z_{3}^{\text {nadir }}=\max \left(Z_{3}\left(x_{1}^{\text {optimal }}\right) \text { and } Z_{3}\left(x_{2}^{\text {optimal }}\right)\right)
\end{aligned}
$$

Step 6: Identify a linear membership function for 
each objective function using Eqs. (108) to (110).

$$
\begin{aligned}
& \left(\begin{array}{ll}
1 & \text { if } Z_{1} \leq Z_{1}^{\text {optimal }}
\end{array}\right. \\
& \mu_{1}(x)=\left\{\begin{array}{l}
\frac{Z_{1}^{\text {nadir }}-Z_{1}}{Z_{1}^{\text {nadir }}-Z_{1}^{\text {optimal }}} \quad \text { if } Z_{1}^{\text {optimal }}<Z_{1}<Z_{1}^{\text {nadir }} \\
\text { (108) }
\end{array}\right. \\
& \text { (0 } \quad \text { if } Z_{1} \geq Z_{1}^{\text {nadir }} \\
& \mu_{2}(x)= \begin{cases}1 & \text { if } Z_{2} \geq Z_{2}^{\text {optimal }} \\
\frac{Z_{2}-Z_{2}^{\text {nadir }}}{Z_{2}^{\text {otimal }}-Z_{2}^{\text {nadir }}} & \text { if } Z_{2}^{\text {nadir }}<Z_{2}<Z_{2}^{\text {optimal }} \\
0 & \text { if } Z_{2} \leq Z_{2}^{\text {nadir }}\end{cases} \\
& \mu_{3}(x)= \begin{cases}1 & \text { if } Z_{3} \leq Z_{3}^{\text {optimal }} \\
\frac{Z_{3}^{\text {nadir }}-Z_{3}}{Z_{3}^{\text {nadir }}-Z_{3}^{\text {optimal }}} & \text { if } Z_{3}^{\text {optimal }}<Z_{3}<Z_{3}^{\text {nadir }} \\
0 & \text { if } Z_{3} \geq Z_{3}^{\text {nadir }}\end{cases}
\end{aligned}
$$

where $\mu_{h}(x)$ denotes the satisfaction degree of the $h$ th objective function.

Step 7: This step proposes an FGP approach [27] to attain the most preferable compromise solution for the multi-objective problem. Construct the FGP formulation as follows:

$$
\begin{aligned}
& \max \sum_{h \in H} \alpha_{h}, \\
& \text { s.t. : } \\
& \mu_{z_{h}}\left(x_{i}\right) \geq \alpha_{h} \quad h=1,2, \cdots, H ; i=1,2, \cdots, n, \\
& \alpha_{h} \in[0,1] \\
& x \in Q(x) .
\end{aligned}
$$

In this model, the aim is to attain the maximum satisfaction level, namely $\alpha_{h}$-value, in such a way that the constraints can be satisfied, where $Q(x)$ represents the feasible area concerning the constraints of the equivalent crisp model.

Step 8: After solving the objective function in Step 7 and obtaining $Z_{h}^{\text {Optimal }}$, solve the following function for obtaining new $\alpha_{h}\left(\alpha_{h}^{\text {new }}\right)$ :

$$
\begin{array}{ll}
\max & \sum_{h} \alpha_{h}, \\
\text { s.t. } & \text { Constraint }(112-114) \\
& \alpha_{h}^{\text {new }} \geq \alpha_{h} \quad h=1,2, \cdots, H .
\end{array}
$$

Step 9: Repeat Step 8 and solve it by adding constraint $\alpha_{h}^{\text {new }} \geq \alpha_{h}$ for each " $h$ " and calculate various $\alpha_{h} \mathrm{~s}$.

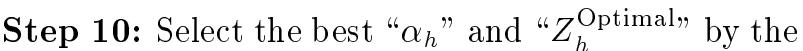
DM.

\subsection{Dragonfly Algorithm (DA)}

Because of the complexity of the CLSC design problems, the problem found NP-hard nature for the large sizes $[28,29]$. The lack of a good algorithm that leads to a near-optimum solution in a rational CPU time to solve the CLSC design problem is still felt [3]. With regard to the complexity of the large-sized problem of the proposed CLSC design, a recently known metaheuristic algorithm, called DA, is proposed to solve.

Mirjalili [30] introduced a new swarm-based algorithm DA to solve single-objective, discrete, and multi-objective problems. The major motivation of the DA relies on the static (feeding) and dynamic (migratory) swarming behaviors of dragonflies. The two swarming behaviors are similar to the main phases of optimization using meta-heuristics: exploration and exploitation. Dragonflies form sub-swarms and fly over the different areas in the static swarm, which is the major purpose of exploration phases. In the dynamic swarm, however, dragonflies fly in bigger swarms and along one direction, which is favorable in the exploitation phase. Mirjalili [30] summarized the behavior of dragonflies as the combination of five steps, namely Separation, Alignment, Cohesion, Attraction towards a food source, and Distraction outwards an enemy:

1. Separation is computed as follows:

$$
s_{i}=-\sum_{j=1}^{N} X-X_{j}
$$

where $X$ provides position of current individual, $X_{j}$ is position of the $j$ th neighboring individual, and $N$ is number of the neighboring individuals.

2. Alignment is calculated as follows:

$$
A_{i}=\frac{\sum_{j=1}^{N} V_{j}}{N},
$$

where $V_{j}$ indicates the velocity of the $j$ th neighboring individual;

3. Cohesion is calculated as follows:

$$
C_{i}=\frac{\sum_{j=1}^{N} X_{i}}{N}-X .
$$

4. Attraction towards food source is computed as follows: 


$$
F_{i}=X^{+}-X
$$

where $X$ and $X^{+}$indicate position of current individual and that of the food source, respectively.

5. Distraction outwards an enemy is calculated as follows:

$$
E_{i}=X^{-}+X
$$

where $X$ and $X^{-}$indicate position of the current individual and that of the enemy, respectively.

Step $(\Delta X)$ vector and position $(X)$ vector are considered to update position of the artificial dragonflies in the search space and simulate the movements of dragonflies. The step vector used in DA is analogous to the velocity vector in Particle Swarm Optimization. Step vector $\Delta X$ shows the direction of movement of the dragonflies. The step vector can be computed as follows:

$$
\Delta X_{t+1}=\left(s S_{i}+a A_{i}+c C_{i}+f F_{i}+e E_{i}\right)+w \Delta X_{t},
$$

where $s, a, c, f, e$, and $w$ indicate weights of separation, alignment, cohesion, food attraction, enemy distraction, and inertia weight, respectively, and $t$ shows iteration count.

After computing the step vector, the position vectors are calculated as follows:

$$
X_{t+1}=X_{t}+\Delta X_{t+1},
$$

where $t$ indicates the current iteration. With separation, alignment, cohesion, food, and enemy factors ( $s$, $a, c, f$, and $e$ ), various explorative and exploitative behaviors can be attained during the optimization process.

The position of dragonflies is updated by means of a random walk (Levy flight) when there is no neighboring solution. Thus, position vectors $X$ are computed as follows:

$$
X_{t+1}=X_{t}+\operatorname{Levy}(d) \times X_{t} .
$$

The neighborhood area is increased too, whereby the swarm becomes one group at the final stage of optimization to converge to the global optimum. Food source and enemy are chosen from the best and worst solutions obtained in the whole swarm at any instant. This causes convergence towards promising regions of the search space and divergence outward non-promising areas of the search space. Pseudo-codes of the DA algorithm are provided in Figure 2.

The GA is known as the best evolutionary algorithm and has been successfully used in a wide range of engineering and combinatorial problems [31]. It has been used as a tool for validating newly developed or extended meta-heuristics in recent years [30]. GA is used as a reference to validate the results of DA.

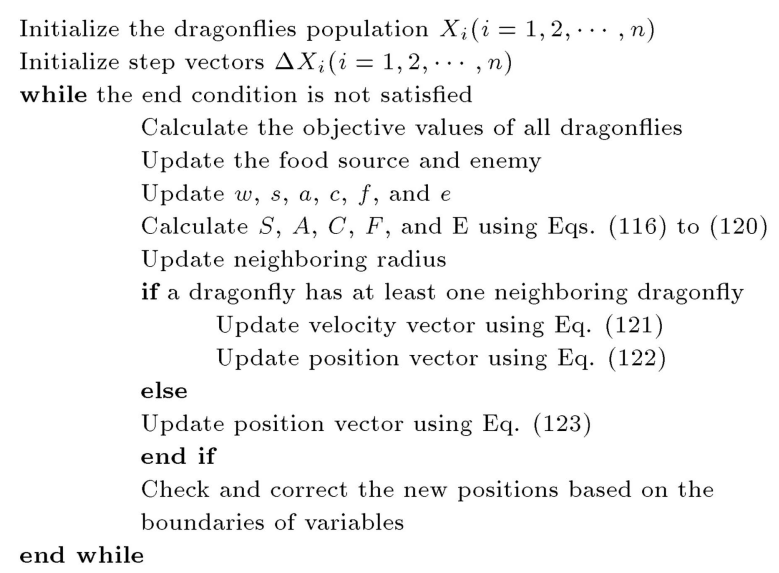

Figure 2. Pseudo-codes of the DA algorithm [30].

\section{Model implementation}

\subsection{Computational case study and data description}

In order to observe the performance of the proposed model and the usefulness of the proposed hybrid solution methodology, a case study whose data originated from the paper industry in East Azerbaijan of Iran is studied. The configuration of the corresponding supply chain is shown in Figure 3. The CLSC network involves two paper plants, three vendors to supply virgin pulps, four potential regional wholesalers, twenty paper dealers, five initial collection centers, one site for a centralized return point, two potential sites for paper recycling facilities, two potential recycling technologies, one energy recovery center, and one site for disposal. There are also four types of paper: glossy, printing and writing, kraft and fluting, four types of virgin pulps and two types of recycled paper. The vehicles available at vendors, manufacturers, regional wholesalers, and government are $4,3,6$, and 3 , respectively. Three scenarios, $s_{1}, s_{2}$, and $s_{3}$, are considered with occurrence probabilities of $0.45,0.3$, and 0.25 , respectively. Note that the subject matter experts extract these scenarios

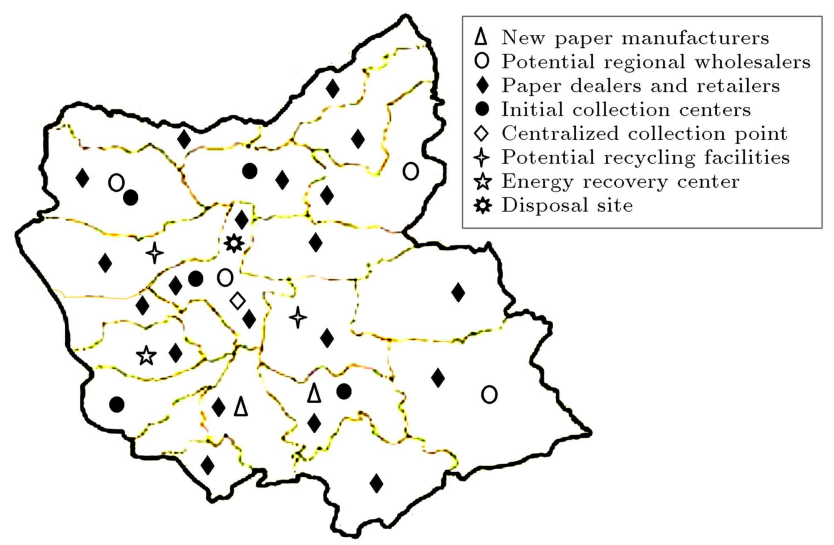

Figure 3. Configuration of the addressed supply chain. 
Table 1. Data used in the illustrative example.

\begin{tabular}{lc}
\hline \multicolumn{1}{c}{ Parameters } & Ranges of value \\
\hline Selling price of waste paper to energy recovery centers (Rial/kg) & {$[500-2400]$} \\
Purchasing cost of virgin pulps from vendors (Rials/kg) & {$[1000-3000]$} \\
Recycling cost using different technologies (Rial/kg) & {$[1000-5000]$} \\
Sorting cost (Rial/kg) & {$[1000-2000]$} \\
Hiring cost of a vehicle (Rial) & {$[900000-7000000]$} \\
Production capacity of paper manufacturers for per paper $(\mathrm{kgs})$ & {$[0-80000000]$} \\
Recycling capacity of different technologies at recycling facilities & {$[15000000-60000000]$} \\
per paper (kgs) & {$[40000000-54000000]$} \\
Supply capacity of vendors per virgin pulp (kgs) & {$[16000-44000]$} \\
Capacity of vehicles (kgs) & {$[300-4000]$} \\
Maximum number of vehicle types & {$[80-90]$} \\
Rate of satisfying the quality specifications for recycling & {$[30-70]$} \\
Recycling rate & {$[20-40]$} \\
Energy recovery rate & {$[20-90]$} \\
Rate of virgin pulp & {$[0-260]$} \\
Distances (km) & 350 \\
Maximum tour distances (km) & 3 \\
Maximum number of opened wholesalers & \\
\hline
\end{tabular}

and their associated probabilities. Data used in the computational case study are given in Tables 1 and 2 .

\subsection{Computational results}

We run the model with data in Tables 1 and 2 through CPLEX solver of the GAMS commercial software version 24.1.3 on a computer Intel(R), Core (TM) i54200M CPU@ $2.50 \mathrm{GHz}$, and $8.00 \mathrm{~GB}$ of RAM to analyze the mixed-integer linear model for the first objective function (total cost minimization), the second one (total volume flexibility maximization), and the third one (total number of vehicles hired minimization) separately as a single objective integer programming. In this way, lower and upper bounds to form fuzzy membership functions are obtained separately. Tables 3 and 4 reveal the details regarding the problem basis of $\lambda=1$ and $\omega=200$.

Solution of the FGP method in the case study yields the following optimal results, as presented in Table 5. It is assumed that the DM is satisfied at the end of iteration 3 with $\alpha_{1}=0.86, \alpha_{2}=1$, and $\alpha_{3}=$ 0.95. Based on Table 5, fuzzy compromise solution, which considers all objectives, simultaneously gives close-by results to the optimal individual solutions for each objective function. The obtained compromise solution is depicted by Figure 4 . With this compromise solution, three of the regional wholesalers and two

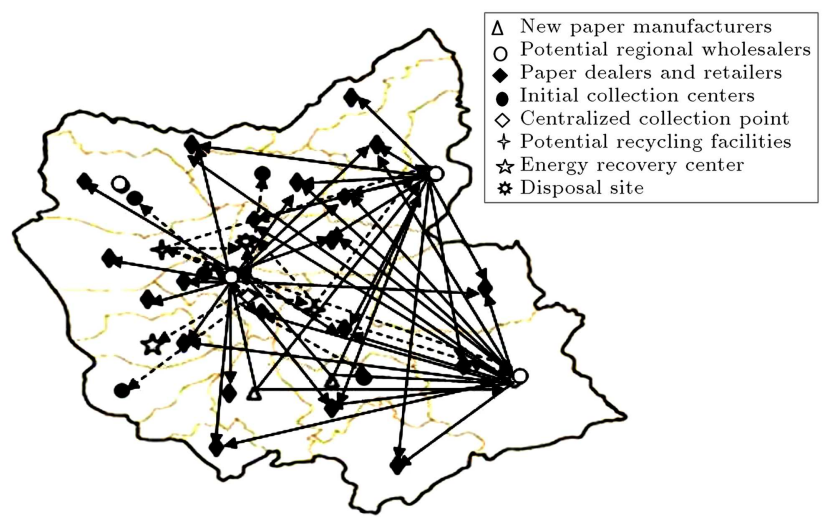

Figure 4. Optimal CLSC configuration, simultaneously considering all of the fuzzy objective functions.

of the paper recycling facilities with two types of technologies are opened.

\subsection{Sensitivity analysis}

In order to investigate the sensitivity of the stochastic robust model and decision parameters to variations of each fuzzy goal, the proposed fuzzy multi-objective problem is resolved with different scenarios in Section 5.3.1. In addition, a sensitivity analysis is performed for model robustness and solution robustness against the multiplier of model robustness $(\omega)$ in Section 5.3.2. 
Table 2. Sources of values in scenarios for illustrative example.

\begin{tabular}{|c|c|c|c|}
\hline \multirow{2}{*}{ Parameters } & \multicolumn{3}{|c|}{ Values } \\
\hline & Scenario 1 & Scenario 2 & Scenario 3 \\
\hline $\begin{array}{l}\text { Fixed setup cost of opening } \\
\text { regional wholesaler } w \\
\text { (million Rial) }\end{array}$ & [3200-5900] & [6800-9800] & {$[5200-7400]$} \\
\hline $\begin{array}{l}\text { Fixed setup cost of opening } \\
\text { recycling facility } r \\
\text { (million Rial) }\end{array}$ & {$[5000-6000]$} & {$[6000-7000]$} & {$[5500-6500]$} \\
\hline $\begin{array}{l}\text { Fixed setup cost of opening } \\
\text { recycling facility } r \text { using } \\
\text { technology } h \text { (million Rial) }\end{array}$ & {$[5900-8000]$} & {$[3800-6500]$} & {$[2500-4000]$} \\
\hline Production cost (Rial/kg) & [9500-25000] & [38000-65000] & [25000-40000] \\
\hline Transportation cost (Rial/ km) & Uniform (100-400) & Uniform (400-600) & Uniform (300-500) \\
\hline $\begin{array}{l}\text { Transportation cost for } \\
\text { waste paper (Rial/kg) }\end{array}$ & Uniform (1-3) & Uniform (2-4) & Uniform $(3-5)$ \\
\hline $\begin{array}{l}\text { Transportation cost for } \\
\text { recycled paper (Rial/kg) }\end{array}$ & Uniform (1-3) & Uniform (2-3) & Uniform (1-2) \\
\hline $\begin{array}{l}\text { Purchasing cost of waste } \\
\text { paper from waste vendors } \\
(\text { Rial } / \mathrm{kg})\end{array}$ & [1000-2000] & {$[3000-4000]$} & [2000-3000] \\
\hline $\begin{array}{l}\text { Selling price of waste paper to } \\
\text { waste customers } \\
(\text { Rial } / \mathrm{kg})\end{array}$ & [1500-3000] & [1000-2000] & [3000-4000] \\
\hline Collection cost (Rial $/ \mathrm{kg})$ & {$[2000-3000]$} & {$[3000-4000]$} & {$[2500-3500]$} \\
\hline Disposal cost (Rial/kg) & [1000-3000] & [2000-3000] & [1000-2000] \\
\hline $\begin{array}{l}\text { Demand forecasts of new paper } \\
\text { dealers (kgs) }\end{array}$ & Uniform (640000-1000000) & Uniform (2000000-3200000) & Uniform (1000000-2200000) \\
\hline $\begin{array}{l}\text { Demand forecasts of recycled } \\
\text { paper dealers }(\mathrm{kgs})\end{array}$ & Uniform (100000-300000) & Uniform (550000- 800000) & Uniform (250000-600000) \\
\hline $\begin{array}{l}\text { Returned volume of per waste } \\
\text { paper to the initial } \\
\text { collection center }(\mathrm{kgs})\end{array}$ & Uniform (1500000- 2800000) & Uniform (180000-800000) & Uniform (450000-1500000) \\
\hline $\begin{array}{l}\text { Storage capacity of regional } \\
\text { wholesalers }(\mathrm{kgs})\end{array}$ & [500000000-700000000] & [800000000-950000000] & [100000000-950000000] \\
\hline $\begin{array}{l}\text { Storage capacity of centralized } \\
\text { collection point }(\mathrm{kgs})\end{array}$ & [1000000000-1170000000] & [850000000-950000000] & [900000000-1050000000] \\
\hline Disposal rate & Uniform (6-8) & Uniform (7-9) & Uniform $(8-10)$ \\
\hline
\end{tabular}


Table 3. Optimization results obtained from the stochastic robust model solution considering objective functions separately.

\begin{tabular}{lccc}
\hline & Total cost & $\begin{array}{c}\text { Total volume } \\
\text { flexibility }\end{array}$ & $\begin{array}{c}\text { Total number of } \\
\text { vehicles hired }\end{array}$ \\
\hline Total number of variables & 13396 & 13396 & 13396 \\
Total number of constraints & 9513 & 9513 & 9513 \\
Total number of iterations & 162364 & 6925 & 75570 \\
Total value of the CLSC & $8.368 \mathrm{E} 12$ & $1.75213 \mathrm{E} 9$ & 17039.880 \\
Solving time (second) & 586.376 & 41.278 & 168.435 \\
Number of opened paper recycling facilities & 1 & 2 & 2 \\
Number of opened regional wholesalers & 2 & 2 & 3 \\
Number of activated technologies & 1 & 2 & 2 \\
\hline
\end{tabular}

Table 4. Lower and upper bounds of each objective function.

\begin{tabular}{lcc}
\hline \multicolumn{1}{c}{ Goals } & Lower bound & Upper bound \\
\hline Total cost & $8.368 \mathrm{E} 12$ & $1.0964 \mathrm{E} 13$ \\
Total volume flexibility & $9.052803 \mathrm{E} 8$ & $1.75213 \mathrm{E} 9$ \\
Total number of vehicles hired & 17039.880 & 21805.150 \\
\hline
\end{tabular}

Table 5. Results of the fuzzy optimization.

\begin{tabular}{ccccc}
\hline Total cost & $\begin{array}{c}\text { Total volume } \\
\text { flexibility }\end{array}$ & $\begin{array}{c}\text { Total number of } \\
\text { vehicles hired }\end{array}$ & $\begin{array}{c}\text { Solving time } \\
\text { (second) }\end{array}$ & $\begin{array}{c}\text { Total number of } \\
\text { variables-constraints }\end{array}$ \\
\hline $8.73743 \mathrm{E} 12$ & $1.656653 \mathrm{E} 9$ & 17259.260 & 1107.638 & $13400-9517$ \\
\hline
\end{tabular}

Table 6. Application data of different scenarios.

\begin{tabular}{|c|c|c|c|c|c|}
\hline \multirow{2}{*}{ Scenario } & Item & \multirow{2}{*}{ Scenario } & \multirow{2}{*}{$\begin{array}{c}\text { Item } \\
N\end{array}$} & \multirow{2}{*}{ Scenario } & \multirow{2}{*}{$\begin{array}{c}\text { Item } \\
\max _{v w}\end{array}$} \\
\hline & $\operatorname{Recap}_{p r h}(\mathrm{~kg})$ & & & & \\
\hline Scenario 1 & $-25 \%$ & Scenario 4 & 2 & Scenario 7 & -300 \\
\hline Scenario 2 & $+25 \%$ & Scenario 5 & 3 & Scenario 8 & +500 \\
\hline Scenario 3 & $+50 \%$ & Scenario 6 & 4 & Scenario 9 & +700 \\
\hline
\end{tabular}

\subsubsection{Sensitivity analysis of decision parameters}

Evaluating the sensitivity by changing recycling capacity of different technologies at recycling facilities is performed in Scenarios 1-3. In Scenarios 4-6, the variations of each fuzzy goal are analyzed, changing the maximum number of opened regional wholesalers. Evaluating the sensitivity by changing maximum number of vehicle types available at regional wholesalers is performed in Scenarios 7-9. Sensitivity analysis applies to scenarios by the data given in Table 6 . Different upper and lower bounds are obtained for each scenario while considering each scenario. For this reason, the boundary values of the fuzzy goals vary. In other words, when the max-min bounds of the fuzzy goals will vary in each scenario, membership functions should be modified for each scenario before performing each scenario. The boundary values of each objective are revised for each scenario, as given in Table 7. Similarly, membership functions should be redefined by using these max-min boundary values.

For instance, the lower bound for total CLSC costs will decrease if recycling capacity of technology increases, as illustrated in Table 7. Furthermore, higher recycling capacities increase the total volume flexibility as can be seen from the upper bounds. However, it has no effect on the total number of vehicles hired.

The lower bound for the total CLSC cost is not affected by the increasing number of opened regional wholesalers. The upper bound of the total volume flexibility increases and the lower bound of total number of vehicles hired decreases when the maximum number of opened facilities is increased as given in Table 7 .

The lower bound for the total CLSC cost will decrease if the maximum number of vehicle types available at regional wholesaler increases, as given in Table 7. On the other hand, the lower bound of total 
Table 7. Boundaries of the objectives for scenarios.

\begin{tabular}{|c|c|c|c|c|c|c|}
\hline \multirow{4}{*}{ Scenario } & \multicolumn{6}{|c|}{ Objectives } \\
\hline & \multicolumn{2}{|c|}{ Total cost } & \multicolumn{2}{|c|}{$\begin{array}{c}\text { Total volume } \\
\text { flexibility }\end{array}$} & \multicolumn{2}{|c|}{$\begin{array}{c}\text { Total number of } \\
\text { vehicles hired }\end{array}$} \\
\hline & Lower & Upper & Lower & Upper & Lower & Upper \\
\hline & bound & bound & bound & bound & bound & bound \\
\hline Scenario 1 & $8.525 \mathrm{E} 12$ & $1.254 \mathrm{E} 13$ & $8.91267 \mathrm{E} 8$ & $1.22215 \mathrm{E} 9$ & 17039.880 & 22375.240 \\
\hline Scenario 2 & 7.861E12 & $1.035 \mathrm{E} 13$ & $9.45917 \mathrm{E} 8$ & $1.96842 \mathrm{E} 9$ & 17039.880 & 21892.021 \\
\hline Scenario 3 & 7.359E12 & $9.897 \mathrm{E} 12$ & $9.86235 \mathrm{E} 8$ & $2.49751 \mathrm{E} 9$ & 17039.880 & 20541.022 \\
\hline Scenario 4 & 8.368E12 & $1.042 \mathrm{E} 13$ & $8.75427 \mathrm{E} 8$ & $1.46420 \mathrm{E} 9$ & 17538.840 & 21763.050 \\
\hline Scenario 5 & 8.368E12 & $1.096 \mathrm{E} 13$ & $9.05280 \mathrm{E} 8$ & $1.75213 \mathrm{E} 9$ & 17039.880 & 20861.350 \\
\hline Scenario 6 & 8.368E12 & $9.641 \mathrm{E} 12$ & $9.64156 \mathrm{E} 8$ & $2.02773 \mathrm{E} 9$ & 16817.140 & 21593.100 \\
\hline Scenario 7 & $8.375 \mathrm{E} 12$ & $1.059 \mathrm{E} 13$ & $9.03569 \mathrm{E} 8$ & $1.75213 \mathrm{E} 9$ & 16829.200 & 22577.230 \\
\hline Scenario 8 & $8.362 \mathrm{E} 12$ & $1.074 \mathrm{E} 13$ & $9.05280 \mathrm{E} 8$ & $1.75213 \mathrm{E} 9$ & 17878.760 & 21589.500 \\
\hline Scenario 9 & $8.358 \mathrm{E} 12$ & $1.127 \mathrm{E} 13$ & $9.25439 \mathrm{E} 8$ & $1.75213 \mathrm{E} 9$ & 18241.890 & 21685.480 \\
\hline
\end{tabular}

number of vehicles hired increases when the maximum number of vehicle types increases. However, it has no effect on total volume flexibility. The given results are valid just for the cases in which the objectives are considered separately. Results of scenario analysis for simultaneous consideration of fuzzy objectives after two iterations are given in Figure 5.

Application of scenarios in the proposed model yields the following satisfaction degrees for each fuzzy goal, as shown in Figure 5.

In Scenarios 1-3, different recycling capacities of technologies are taken into account. According to Table 7, higher recycling capacities yield cost reduction when the objectives are considered separately.
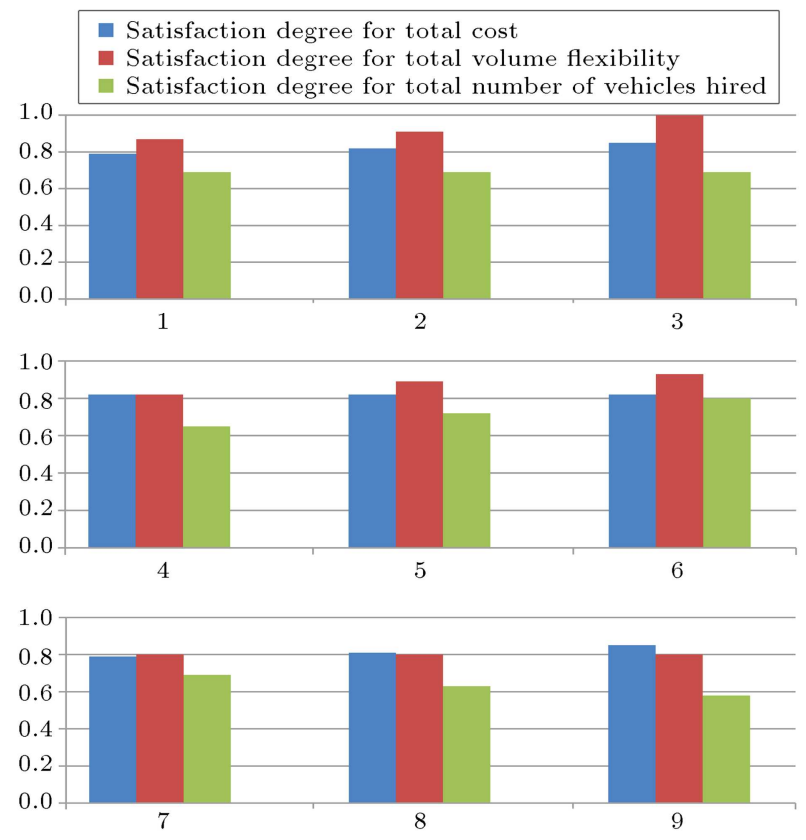

Figure 5. Satisfaction degrees as the results of the scenarios.
However, it is clearly understood from Figure 5 that higher recycling capacities provide lower costs, higher volume flexibility, and equal number of vehicles hired considering all fuzzy goals simultaneously.

In Scenarios 4-6, effects of the maximum number of opened regional wholesalers are examined. According to Figure 5, when the maximum number of opened facilities increases, the total volume flexibility increases and total number of vehicles hired decreases. Moreover, the satisfaction degree for the total cost will not decrease too much due to operating one more regional wholesaler.

In Scenarios 7-9, effects of the increasing number of vehicle types available at regional wholesalers are examined. According to Table 7, the higher number of vehicle types yields a cost reduction when the objectives are considered separately. However, based on Figure 5, the higher number of vehicle types provides lower cost and equal volume flexibility and higher number of vehicles hired considering all fuzzy goals simultaneously. In summary, DMs should increase the number of opened regional wholesalers in order to increase total volume flexibility and decrease the total number of vehicles hired. They may increase the recycling capacities of technologies in order to decrease total cost and increase the total volume flexibility. Furthermore, they may increase the maximum number of vehicle types in order to decrease total cost or decrease the maximum number of vehicle types in order to decrease the number of vehicles hired.

\subsubsection{Sensitivity analysis based on multiplier of model robustness}

Figure 6 presents the trade-off between the first objective function and the increasing dissatisfaction with storage capacity amount of regional wholesalers. When weight $\omega$ increases, the first objective function 


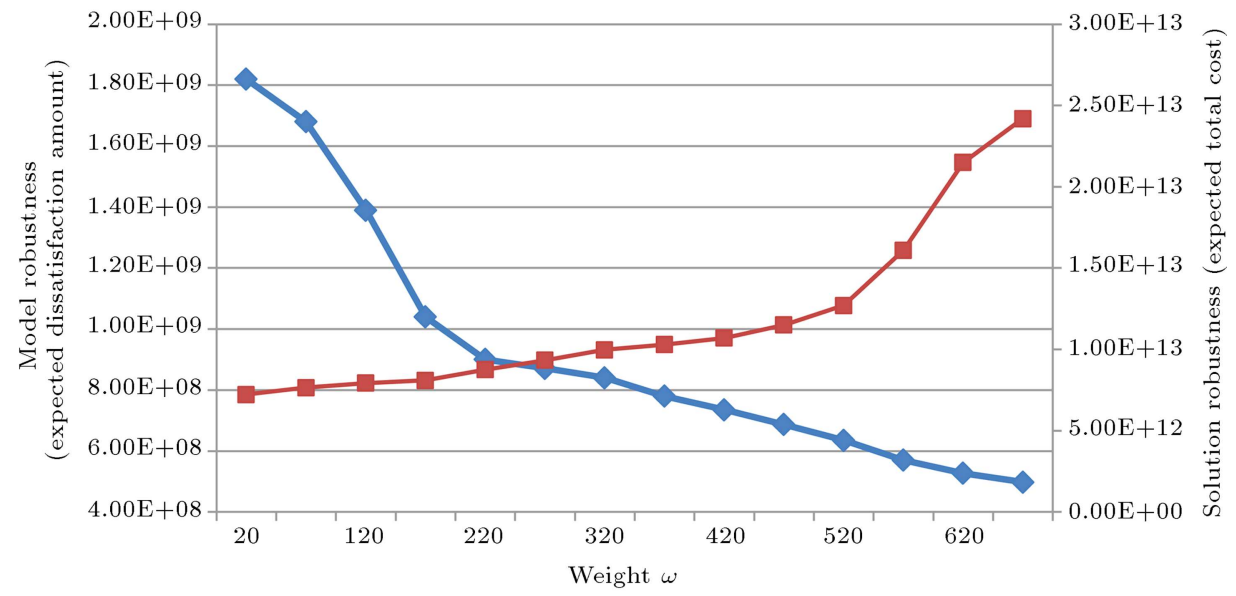

Figure 6. Trade-off between the expected total cost and the expected dissatisfaction amount.

(expected total cost) presenting solution robustness increases, and the expected increasing dissatisfaction with storage capacity amount of regional wholesalers presenting model robustness decreases. This shows that, for higher values of $\omega$, the solution achieved is drawing near "almost" feasible for any realization of scenario by the payment of more total costs. Furthermore, the total expected dissatisfaction amount will decrease to zero with an increase in the value of $\omega$ [32]. This indicates that a higher expected cost could ensure high reliability. In addition, the result will lead to higher failure risk by approaching a lower expected total cost.

\section{Comparisons of two meta-heuristic algorithms}

The performance comparisons of two meta-heuristic algorithms are investigated in this section. The algorithms were coded in MATLAB software Version 7.10.0.499, R2010a environment, and the experiments were performed on a computer Intel(R), Core (TM) i54200M CPU@ $2.50 \mathrm{GHz}$, and $8.00 \mathrm{~GB}$ of RAM to estimate the response functions. To compare and evaluate the performances of the solution methodologies under different environments, the experiments were carried out on 10 test problems, as reported in Table 8. Then, these test problems were solved by DA and GA.

According to the summary of the results shown in Table 9, both DA and GA can be used to optimize large scales of the proposed problem at the suitable times. However, based on Figure 7, the computational time for DA is low compared to GA. Furthermore, the performance of DA is better than GA from an objective point of view as shown for the total cost in Figure 8. Moreover, the Number of Function Evaluation (NFE) of algorithms is shown in Figure 9. As observed, the NFE of GA increases with dimensions and much greater than that of DA. The function evaluation of CLSC problem has the high computational time and the better algorithm has the low NFE. Overall, the results show that DA has the necessary performance. Figure 10 depicts convergence characteristic of DA for objectives of test problem 5 .

Table 8. Generated test problem.

\begin{tabular}{cccccccc}
\hline Problem no & $\boldsymbol{P}$ & $\boldsymbol{P}^{\prime}$ & $\boldsymbol{I}$ & $\boldsymbol{W}$ & $\boldsymbol{K}$ & $\boldsymbol{J}$ & $\boldsymbol{R}$ \\
\hline 1 & 2 & 1 & 1 & 2 & 4 & 2 & 1 \\
2 & 2 & 1 & 1 & 2 & 5 & 4 & 1 \\
3 & 3 & 1 & 1 & 3 & 10 & 4 & 1 \\
4 & 4 & 1 & 1 & 3 & 10 & 5 & 1 \\
5 & 4 & 2 & 1 & 5 & 10 & 5 & 1 \\
6 & 4 & 2 & 2 & 5 & 10 & 5 & 2 \\
7 & 4 & 2 & 2 & 5 & 15 & 5 & 2 \\
8 & 5 & 3 & 4 & 5 & 15 & 5 & 3 \\
9 & 5 & 3 & 4 & 5 & 20 & 5 & 4 \\
10 & 7 & 3 & 5 & 5 & 25 & 5 & 5 \\
\hline
\end{tabular}

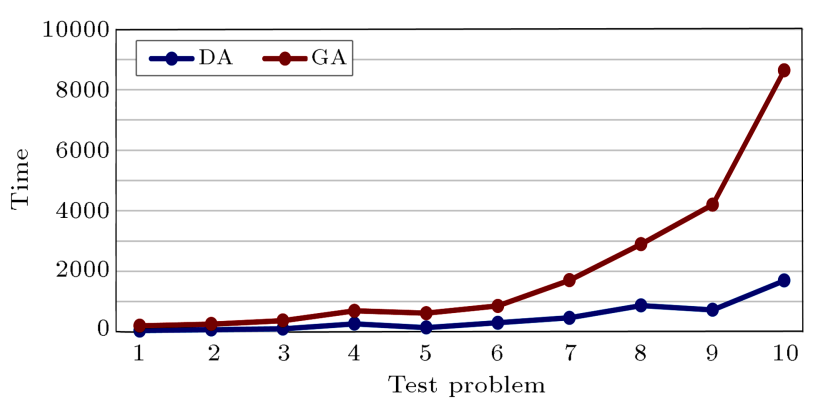

Figure 7. Variation of the computational time for DA and GA.

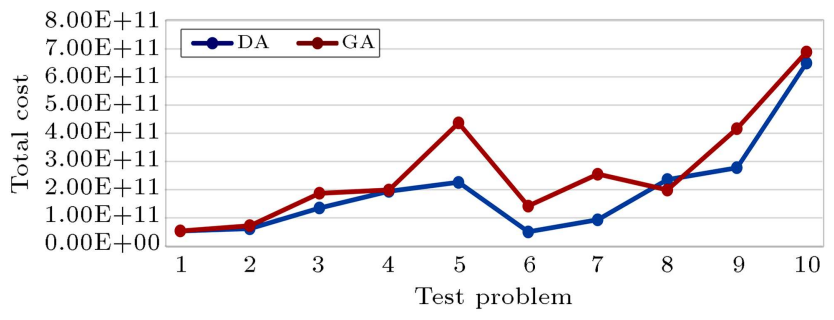

Figure 8. Variation of Total cost for DA and GA. 
Table 9. Test results for problems 1 to 10 .

\begin{tabular}{|c|c|c|c|c|c|c|c|c|c|c|c|}
\hline \multirow{2}{*}{ Solver } & \multirow{2}{*}{ Values } & \multicolumn{10}{|c|}{ Test problems } \\
\hline & & 1 & 2 & 3 & 4 & 5 & 6 & 7 & 8 & 9 & 10 \\
\hline \multirow{7}{*}{ DA } & $Z_{1}$ & $5.34 \mathrm{E}+10$ & $6.15 \mathrm{E}+10$ & $1.35 \mathrm{E}+11$ & $1.94 \mathrm{E}+11$ & $2.26 \mathrm{E}+11$ & $5.01 \mathrm{E}+10$ & $9.33+10$ & $2.36 \mathrm{E}+11$ & $2.78 \mathrm{E}+11$ & $6.50 \mathrm{E}+11$ \\
\hline & $Z_{2}$ & $1.04 \mathrm{E}+09$ & $1.38 \mathrm{E}+09$ & $2.64 \mathrm{E}+09$ & $2.77 \mathrm{E}+09$ & $3.19 \mathrm{E}+09$ & $3.29 \mathrm{E}+09$ & $4.93 \mathrm{E}+09$ & $4.86 \mathrm{E}+09$ & $6.68 \mathrm{E}+09$ & $8 \mathrm{E}+09$ \\
\hline & $Z_{3}$ & 3229.25 & 5094.75 & 10548.75 & 8082 & 8403.25 & 10124.75 & 12289.25 & 16653 & 24507.25 & 45230.75 \\
\hline & $\alpha_{1}$ & 0.99 & 0.98 & 0.97 & 0.94 & 0.93 & 0.97 & 0.94 & 0.96 & 0.91 & 0.88 \\
\hline & $\alpha_{2}$ & 1 & 0.92 & 0.91 & 1 & 0.90 & 0.91 & 0.87 & 0.89 & 0.88 & 0.86 \\
\hline & $a_{3}$ & 0.87 & 0.84 & 0.84 & 0.83 & 0.83 & 0.80 & 0.83 & 0.87 & 0.81 & 0.89 \\
\hline & $\begin{array}{c}\text { Time } \\
\text { (second) }\end{array}$ & 37.90439 & 73.03492 & 103.7836 & 265.6613 & 140.9884 & 298.2505 & 463.2474 & 868.7384 & 726.9302 & 1695.439 \\
\hline \multirow{7}{*}{ GA } & $Z_{1}$ & $5.35 \mathrm{E}+10$ & $7.23 \mathrm{E}+10$ & $1.87 \mathrm{E}+11$ & $1.991 \mathrm{E}+11$ & $4.37 \mathrm{E}+11$ & $1.42 \mathrm{E}+11$ & $2.55 \mathrm{E}+11$ & $1.99 \mathrm{E}+11$ & $4.17 \mathrm{E}+11$ & $6.89 \mathrm{E}+11$ \\
\hline & $Z_{2}$ & $1.04 \mathrm{E}+09$ & $1.38 \mathrm{E}+09$ & $2.64 \mathrm{E}+09$ & $2.77 \mathrm{E}+09$ & $3.13 \mathrm{E}+09$ & $3.29 \mathrm{E}+09$ & $4.93 \mathrm{E}+09$ & $4.85 \mathrm{E}+09$ & $6.65 \mathrm{E}+09$ & $8.24 \mathrm{E}+09$ \\
\hline & $Z_{3}$ & 3268.75 & 4804.5 & 10725.75 & 7780.5 & 8533.75 & 10307 & 12400 & 16606.25 & 24447.25 & 45441.75 \\
\hline & $\alpha_{1}$ & 0.98 & 0.91 & 0.93 & 0.92 & 0.90 & 0.94 & 0.92 & 0.93 & 0.79 & 0.95 \\
\hline & $\alpha_{2}$ & 1 & 0.92 & 0.91 & 1 & 0.89 & 0.91 & 0.87 & 0.88 & 0.87 & 0.87 \\
\hline & $\alpha_{3}$ & 0.86 & 0.86 & 0.85 & 0.86 & 0.80 & 0.82 & 0.80 & 0.88 & 0.82 & 0.81 \\
\hline & $\begin{array}{c}\text { Time } \\
\text { (second) }\end{array}$ & 196.4659 & 255.7811 & 369.1205 & 690.9387 & 613.677 & 856.4295 & 1703.841 & 2897.971 & 4202.405 & 8642 \\
\hline
\end{tabular}

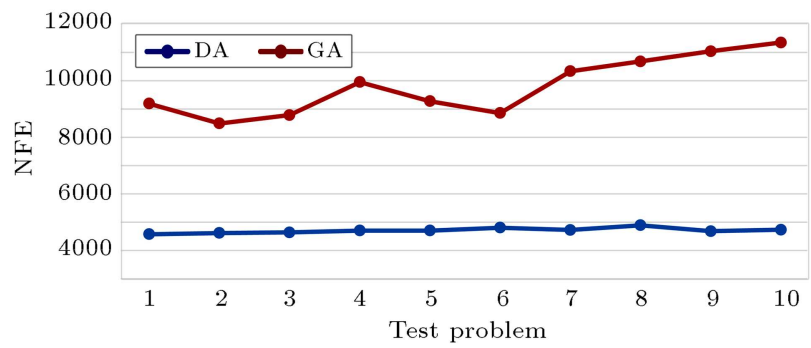

Figure 9. Variation of NFE for DA and GA.

\section{Conclusion and future research}

In this study, a new mixed integer non-linear programming model was developed for a multi-objective, multi-echelon, multi-product CLSC in paper industry including alternative recovery options such as recycling with technology selection and energy recovery under uncertainty. The proposed model attempted to minimize the total cost of the CLSC to maximize the total volume flexibility and, finally, to minimize the total number of vehicles hired. Moreover, a novel solution was developed by combining stochastic programming, robust optimization, and FGP. Furthermore, the proposed model was applied to an illustrative example designed by utilizing real data of the paper industry in Iran. Furthermore, a recently developed DA has been employed to solve the given problem on large scales and compared with GA.

From the case study, we can conclude that the proposed model improves all the three objectives and offers important managerial insights. DMs should increase the number of opened regional wholesalers in order to increase total volume flexibility and decrease the total number of vehicles hired. They may increase the recycling capacities of technologies in order to
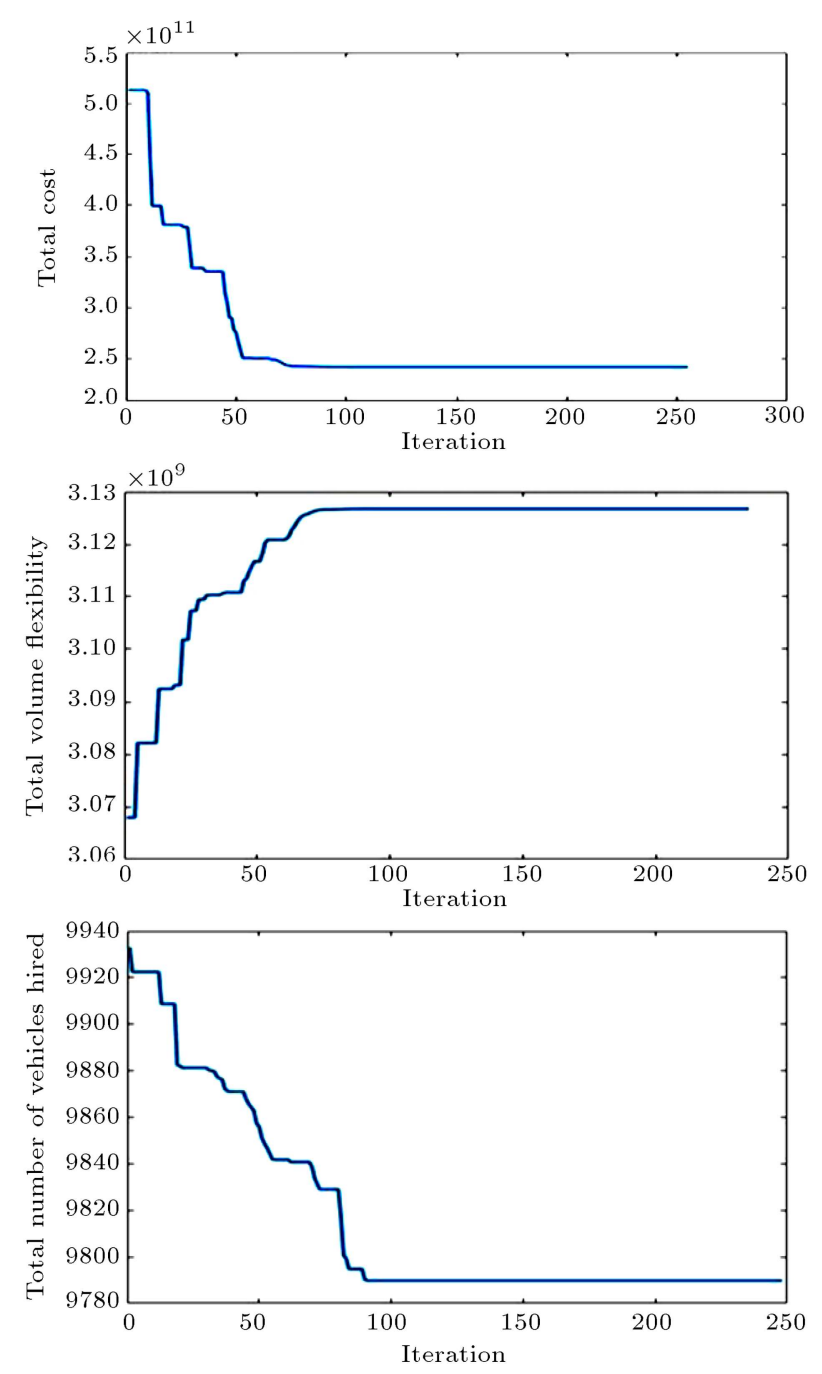

Figure 10. Convergence of DA for objectives of test problem 5 . 
decrease total cost and increase the total volume flexibility. Furthermore, they may increase the maximum number of vehicle types in order to decrease total cost or decrease maximum number of vehicle types in order to decrease the number of vehicles hired. In addition, the large-scale results indicated that the DA achieved better performance in terms of the computational times, objectives, and NFEs compared with the GA.

The green supply chain problem can be considered as a direction for further research; for solving this kind of problem, other methods (e.g., chance-constrained programming) are suggested. Considering multiple time periods and making decisions for each period of time can be a good idea for the future studies. Integrating operational decisions, such as inventory, may also be useful.

\section{References}

1. http://www.paperonweb.com/Iran.htm

2. Yarahmadi, M., Salehi, N., and Salari, H. "Practical strategies to reduce the amount of paper consumption: as study on Iranian paper industry", Indian Journal of Fundamental and Applied Life Sciences, 4, pp. 22316345 (2014).

3. Govindan, K., Soleimani, H., and Kannan, D. "Reverse logistics and closed-loop supply chain: A comprehensivereview to explore the future", European Journal of Operational Research, 240(3), pp. 603-626 (2015).

4. Uster, H., Easwaran, G., Akcali, E., and Cetinkaya, $\mathrm{S}$. "Benders decomposition with alter-native multiple cuts for a multi-product closed-loop supply chain network design model", Naval Res Logist, 54, pp. 890907 (2007).

5. Fleischmann, M., Bloemhof-Ruwaard, J.M., Beullens, P., and Dekker, R. "Reverse logistics network design", In Reverse Logistics: Quantitative Models for ClosedLoop Supply Chains, R. Dekker, M. Fleischmann, K. Inderfurth, \& L.N. VanWassenhove, Eds., pp. 65-94, Springer, Berlin (2004).

6. Du, F. and Evans, G.W. "A bi-objective reverse logistics network analysis for post-sale service", Computers \& Operations Research, 35, pp. 2617-2634 (2008).

7. Pishvaee, M.S., Farahani, R.Z., and Dullaert, W.A. "Memetic algorithm for bi-objective integrated forward/reverse logistics network design", Computers \& Operations Research, 37(6), pp. 1100-1112 (2010).

8. Pishvaee, M.S. and Torabi, S.A.A. "Possibilistic programming approach for closed-loop supply chain network design under uncertainty", Fuzzy Sets and Systems, 161, pp. 2668-2683 (2010).

9. Mirakhorli, A. "Multi-objective optimization of reverse logistics network with fuzzy demand and return- product using an interactive fuzzy goal programming approach", 40th International Conference on Computers and Industrial Engineering (CIE), pp. 1-6 (2010).
10. Khajavi, L.T., Seyed-Hosseini, S.M., and Makui, A. "An integrated forward/reverse logistics network optimization model for multi-stage capacitated supply chain", iBusiness, 3, pp. 229-35 (2011).

11. Zegordi, S.H., Eskandarpour, M., and Nikbakhsh, E.A. "Novel bi-objective multi-product post-sales reverse logistics network design model", Proceedings of the World Congress on Engineering (2011).

12. Zarandi, M.H.F., Sisakht, A.H., and Davari, S. "Design of a closed-loop supply chain model using an interactive fuzzy goal programming", Int. J. Adv. Manuf. Technol., 56, pp. 809-21 (2011).

13. Amin, S.H. and Zhang, G. "A multi-objective facility location model for closed-loop supply chain network under uncertain demand and return", Applied Mathematical Modelling, 37(6), pp. 4165-4176 (2013).

14. Özkır, V. and Başlıgil, H. "Multi-objective optimization of closed-loop supply chains in uncertain environment", Journal of Cleaner Production, 41, pp. 114-125 (2013).

15. Subulan, K., Baykasoglu, A., Özsoydan, F.B., Tasan, A.S., and Selim, H.A. "Case-oriented approach to a lead/acid battery closed-loop supply chain network design under risk and uncertainty", Journal of Manufacturing Systems, 37, pp. 340-361 (2015).

16. Vahdani, B. and Mohamadi M. "A bi-objective interval-stochastic robust optimization model for designing closed loop supply chain network with multipriority queuing system", Intern. Journal of Production Economics, 170, pp. 67-87 (2015).

17. Kadambala, D.K., Subramanian, N., Tiwari, M.K., Abdulrahman, M., and Liu, C. "Closed loop supply chain networks: Designs for energy and time value efficiency", Intern. Journal of Production Economics, 183, pp. 382-393 (2016).

18. Soleimani , H., Govindan, K., Saghafi, H., and Jafari, H. "Fuzzy multi-objective sustainable and green closed-loop supply chain network design", Computers \& Industrial Engineering, 109, pp. 191-203 (2017).

19. Paydar, M.M., Babaveisi, V., and Safaei, A.S. "An engine oil closed-loop supply chain design considering collection risk", Computers \& Chemical Engineering, 104, pp. 38-55 (2017).

20. Ucuncu, A. and Vesilind, P.A. "Energy recovery from mixed paper waste", Waste Manag. Res., 11, pp. 507513, (1993).

21. Slack, N. "The flexibility of manufacturing systems", Int. J. Oper. Prod Manag., 7, pp. 35-45 (1987).

22. Sabri, E.H. and Beamon, B.M. "A multi-objective approach to simultaneous strategic and operational planning in supply chain design", Omega, 28, pp. 58198 (2000). 
23. Subulan, K. "Modelling strategic and tactical planning problems in closed-loop supply chains under crisp and fuzzy environments", Master's Thesis, University of Dokuz Eylül, Izmir, Turkey (2012).

24. Vickery, S.N., Calantone, R., and Dröge, C. "Supply chain flexibility: An empirical study", J. Supply Chain Manag., 35(3), pp. 16-24 (1999).

25. Garge, K., Kannan, D., Diabat, A., and Jha, P.C. "A multi-criteria optimization approach to manage environmental issues in closed loop supply chain network design", Journal of Cleaner Production, 100, pp. 297314 (2015).

26. Mirzapour Al-e-hashem, S.M.J., Malekly, H., and Aryanezhad, M.B. "A multi-objective robust optimization model formulation product multi-site aggregate production planning in a supply chain under uncertainty", Int. J. Production Economics, 134, pp. 28-42 (2011).

27. Ghodratnama, A., Tavakkoli-Moghaddam, R., and Azaron, A. "Robust and fuzzy goal programming optimization approaches for a novel multi-objective hub location-allocation problem: A supply chain overview", Applied Soft Computing, 37, pp. 255-276 (2015).

28. Syarif, A., Yun, Y., and Gen, M. "Study on multistage logistic chain network: A spanning tree-based genetic algorithm approach", Computers \& Industrial Engineering, 43, pp. 299-314 (2002).

29. Devika, K., Jafarian, A., and Nourbakhsh, V. "Designing a sustainable closed-loop supply chain network based on triple bottom line approach: A comparison of metaheuristics hybridization techniques", Eur. J. of Oper.Res., 235(3), pp. 594-615 (2014).

30. Mirjalili, S. "Dragonfly algorithm: a new metaheuristic optimization technique for solving singleobjective, discrete, and multi-objective problems", Neural Comput. \& Applications, 27(4), pp. 1053-1073 (2015). DOI $10.1007 / \mathrm{s} 00521-015-1920-1$
31. John, H., Holland, Adaptation in Natural and Artificial Systems, MIT Press, Cambridge (1992).

32. Mulvey, J.M. and Ruszczynski, A. "A new scenario decomposition method for large-scale stochastic optimization", Operations Research, 43, pp. 477-490 (1995).

\section{Biographies}

Arezoo Rahmani Ahranjani is currently a $\mathrm{PhD}$ Student of Industrial Engineering of Science and Research Branch of Islamic Azad University of Tehran. Her specific areas of expertise include logistics and supply chain management, uncertainty and sustainable operations management.

Mehdi Seifbarghy received his $\mathrm{PhD}$ degree from Sharif University of Technology in 2005. He is an Associate Professor of Industrial Engineering of Alzahra University. His areas of expertise include supply chains and reverse logistics; facility location and system analysis and design. He has more than 40 journal papers in the valid international and national journals.

Ali Bozorgi-Amiri is an Assistant Professors of Industrial Engineering of Tehran University. His specific areas of expertise include robust stochastic programming, location-routing problems, supply chain network, and disruption management.

Esmail Najafi is an Assistant Professors of Industrial Engineering of Science and Research Branch of Islamic Azad University of Tehran. His specific areas of expertise include DEA, supply chain, and project management. 